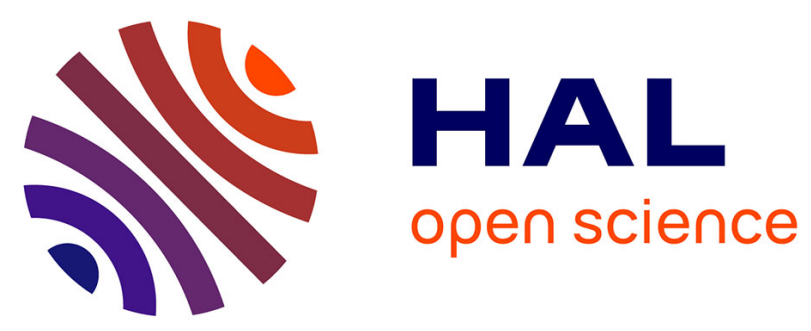

\title{
Polymer-Derived Ultra-High Temperature Ceramics (UHTCs) and Related Materials
}

Emanuel Ionescu, Samuel Bernard, Romain Lucas, Peter Kroll, Sergey V. Ushakov, Alexandra Navrotsky, Ralf Riedel

\section{- To cite this version:}

Emanuel Ionescu, Samuel Bernard, Romain Lucas, Peter Kroll, Sergey V. Ushakov, et al.. PolymerDerived Ultra-High Temperature Ceramics (UHTCs) and Related Materials. Advanced Engineering Materials, 2019, 21 (8), pp.1900269. 10.1002/adem.201900269 . hal-02396855

\section{HAL Id: hal-02396855 \\ https://hal-unilim.archives-ouvertes.fr/hal-02396855}

Submitted on 12 Dec 2020

HAL is a multi-disciplinary open access archive for the deposit and dissemination of scientific research documents, whether they are published or not. The documents may come from teaching and research institutions in France or abroad, or from public or private research centers.
L'archive ouverte pluridisciplinaire HAL, est destinée au dépôt et à la diffusion de documents scientifiques de niveau recherche, publiés ou non, émanant des établissements d'enseignement et de recherche français ou étrangers, des laboratoires publics ou privés. 


\title{
Polymer-Derived Ultra-High Temperature Ceramics (UHTCs) and Related Materials
}

\author{
Emanuel lonescu, * Samuel Bernard, ${ }^{*}$ Romain Lucas, Peter Kroll, Sergey Ushakov, \\ and Alexandra Navrotsky Ralf Riedel
}

Ultra-high temperature ceramics (UHTCs) represent an emerging class of materials capable of providing mechanical stability and heat dissipation upon operation in extreme environments, e.g., extreme heat fluxes, chemically reactive plasma conditions. In the last few decades, remarkable research efforts and progress were done concerning the physical properties of UHTCs as well as their processing. Moreover, there are vivid research activities related to developing synthetic access pathways to UHTCs and related materials with high purity, tunable composition, nano-scaled morphology, or improved sinterability. Among them, synthesis methods considering preceramic polymers as suitable precursors to UHTCs have received increased attention in the last few years. As these synthesis techniques allow the processing of UHTCs from the liquid phase, they are highly interesting, e.g., for the fabrication of ultra-high temperature ceramic composites (UHT CMCs), additive manufacturing of UHTCs, etc. In the present review, UHTCs are in particular discussed within the context of their physical properties as well as energetics. Moreover, various synthesis methods using preceramic polymers to access UHTCs and related materials (i.e., (nano)composites thereof with silica former phases) are summarized and critically evaluated. points and requires that UHTCs melt at temperatures beyond $3000{ }^{\circ} \mathrm{C}$ (sometimes $3000 \mathrm{~K}) .^{[1,2]}$ These materials are relevant mainly for applications which operate at extremely high temperatures (e.g., $T$ $2000{ }^{\circ} \mathrm{C}$ ) and for short times (typically in the order of minutes, sometimes few hours). Within this context (and due to reasons discussed in some detail below), borides, carbides and nitrides of group 4 transition metals are considered to be typical UHTCs, as they offer the fundamental advantage not to melt at these tremendously high temperatures. However, they suffer from poor environmental compatibility (e.g., poor oxidation resistance), so they usually resist UHTs only for a very short exposure time. ${ }^{[3]}$ Secondly, an alternative definition for UHTCs relates to materials which can be used at temperatures higher than those addressed by typical high-temperature ceramics (such as silicon nitride or silicon carbide).$^{[1,2]}$

Thus, materials capable of long-term operation at temperatures beyond $1600^{\circ}$ -

\section{Introduction}

1.1. Definitions, Terms, and Limitations

There are two ways to define ultra-high temperature ceramics (UHTCs). Firstly, a strict definition relates to their melting

\section{Dr. E. Ionescu}

Technische Universität Darmstadt

Fachbereich Material- und Geowissenschaften

Fachgebiet Disperse Feststoffe

Otto-Berndt-Str. 3, D-64287 Darmstadt, Germany

E-mail: ionescu@materials.tu-darmstadt.de

Dr. S. Bernard, Dr. R. Lucas

Univ. Limoges

CNRS, IRCER

UMR 7315, F-87000 Limoges, France samuel.bernard@unilim.fr

Prof. P. Kroll

Department of Chemistry and Biochemistry

University of Texas at Arlington

700 Planetarium Place, Arlington, TX 76019-0065, USA
$\mathrm{C}$ (this temperature is generally accepted as the long-term operation limit for $\mathrm{Si}_{3} \mathrm{~N}_{4}$ or $\mathrm{SiC}$ ) are considered. Their melting points do not necessarily have to exceed $3000{ }^{\circ} \mathrm{C}$ (however, the higher the temperature of melting $\left(T_{\mathrm{m}}\right)$, the better); whereas their operation time should be significantly longer than those of the materials mentioned within the context of the first 


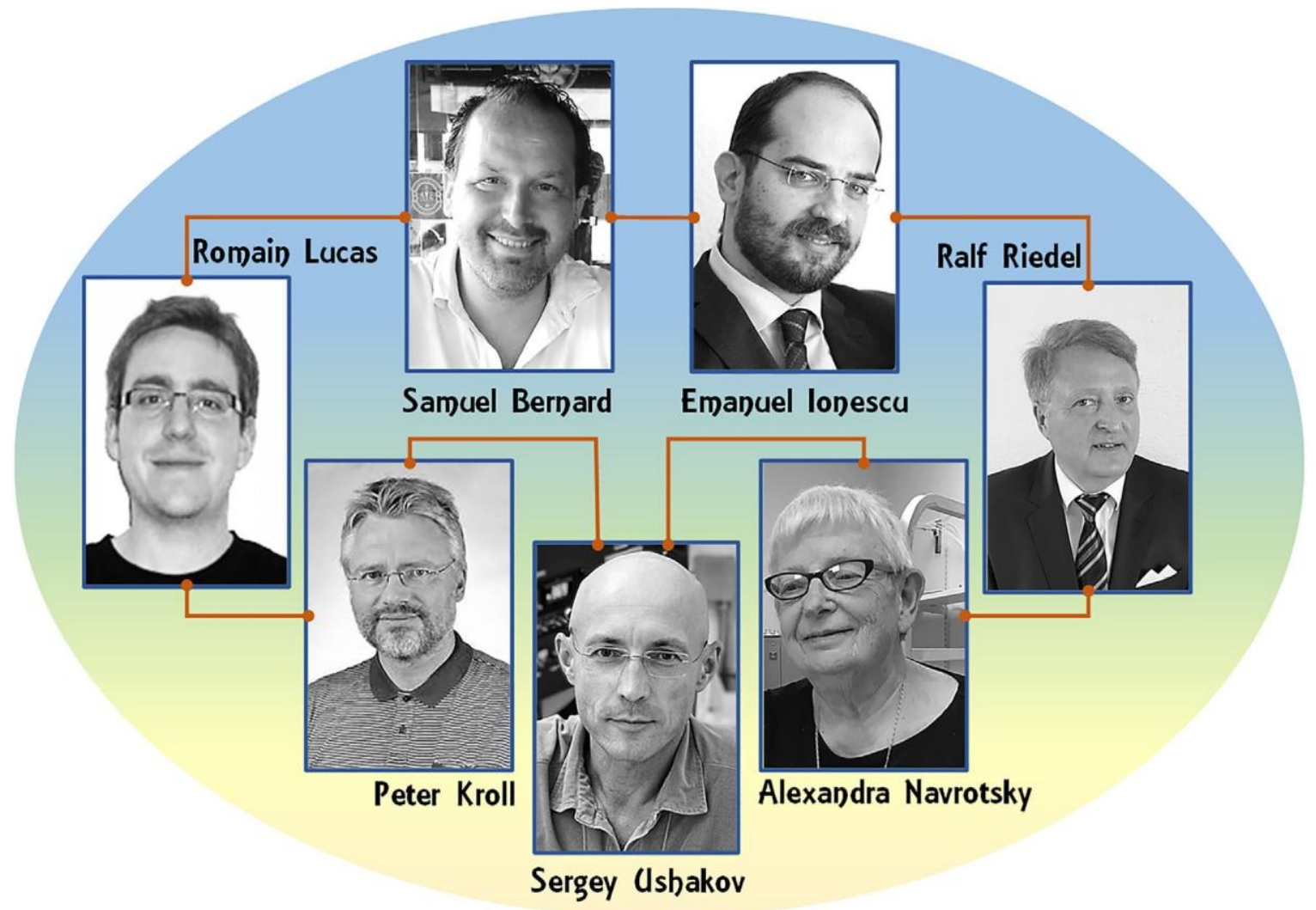

definition. Thus, UHTCs are either 1) materials with $T_{\mathrm{m}}$ higher than $3000{ }^{\circ} \mathrm{C}$ and which can resist $\mathrm{T} 2000{ }^{\circ} \mathrm{C}$ and short exposure times to hostile environments or 2) materials which can withstand $T>1600{ }^{\circ} \mathrm{C}$ and long-term exposure to environmental loading.

When operated at high temperatures (HT) or ultra-high temperatures (UHT) and in extreme environments, structural parts and components are exposed to additional and more severe design constraints as compared to those used in service at or near ambient temperature. ${ }^{[1,4,5]}$ A fundamental property which is required in order to be able to operate materials at (ultra)high temperatures relates to their melting point. Naturally, (ultra)high melting points of the chosen materials are necessary, as usually the maximum operation temperature of a material is round half of its melting point with some exceptions, such as Ni-base superalloys, which can be operated at temperatures up to $90 \%$ of their melting points. ${ }^{[6-9]}$ Moreover, the environmental degradation of the materials becomes critical at high and ultra-high temperatures and consequently materials capable to withstand thermal decomposition as well as oxidation and corrosion should be taken into consideration. Hence, a basic requirement to be fulfilled relates to thermal stability and environmental (chemical) inertness of the materials of choice. Operation of materials at high and ultra-high temperatures is also related to other factors such as thermally induced stresses and time dependent inelastic strain (creep), which may significantly contribute to catastrophic failure of the components during operation. Depending on the failure consequences (i.e., economic vs. safety-related aspects),

those requirements are very strict and materials/components design might suffer here from an extremely high level of conservatism.

Generally, high tolerance to thermal and mechanical stress is desirable in order to avoid catastrophic failure of the materials during operation. Thus, high compliance to thermal stress can be provided by using highly thermal shock resistant materials. Additionally, suitably optimized ductility of the materials or, in the case of brittle (e.g., ceramic based) components, improved fracture toughness is desirable in order to provide high tolerance to mechanical stresses. Finally, no phase transformation of the materials in the range from ambient to operation temperature should occur, as such processes usually are accompanied by significant volume changes which consequently are likely to generate tremendous stresses and induce catastrophic failure. In the case of amorphous materials, increased crystallization resistance may be beneficial for avoiding the generation of mechanical stress upon operation at (ultra)high temperatures. Intense efforts have been made in the last decades to accommodate those requirements, which are often strongly conflicting. Thus, several types and classes of (ultra)hightemperature materials have been proposed and developed over the years, such as highly refractory metals, intermetallics/alloys, metal matrix composites (MMCs) as well as UHTCs or ceramic matrix composites (CMCs).

When trying to identify suitable materials for operation at UHTs and in extreme environments, one major criterion to be taken into account is their melting point. There are more than 300 materials which exhibit a melting temperature above 
$2000{ }^{\circ} \mathrm{C}$, including highly refractory metals (such as $\mathrm{Hf}, \mathrm{Nb}$, $\mathrm{Ta}, \mathrm{W}, \mathrm{Re}, \mathrm{Ir}$ ) and numerous ceramics (oxides, carbides, nitrides, borides). However, only few materials are known to exhibit melting points beyond $3000{ }^{\circ} \mathrm{C}$, among them elements (W, Re, $\mathrm{C})$, as well as binaries with high covalent bonding character (e.g., BN, $\mathrm{ThO}_{2}$ TiC, $\mathrm{ZrC}, \mathrm{ZrB}{ }_{2} \mathrm{HfC}, \mathrm{HfN}, \mathrm{HfB},{ }_{2} \mathrm{bC}, \mathrm{TaC}$,

$\left.\mathrm{TaN}, \mathrm{TaB}_{2}\right){ }^{[1,10]}$ They are denoted as ultra-high temperature ceramics (UHTCs). Beside their ultra-high melting points, UHTC materials should withstand non-steady-state interactions with combustion environments and friction with the atmosphere (as for re-entry vehicles). These extreme conditions strongly limit the number of suitable materials among those presented above.

Thus, materials which are left after considering the mentioned criteria are some group 4 carbides, nitrides and diborides (especially that of zirconium and hafnium). ${ }^{[11]}$ This class of materials was first investigated between the 1950s and 1970s, mainly in former USSR and USA and has received increased attention within the last 10-15 years, due to the efforts in developing hypersonic flight vehicles. ${ }^{[4,12]}$ It has been shown, however, that bulk single-phase UHTCs exhibit rather poor oxidation resistance and damage tolerance under extreme environments. Within this context, the development of UHTCs moved toward composite formulations with improved performance in harsh oxidative environments. Thus, oxidation resistant (mostly particulate) phases have been added to UHTCs, such as $\mathrm{SiC}$ or silicides $\left(\mathrm{TaSi}_{2}, \mathrm{MoSi}_{2}\right.$, etc.). ${ }^{[1,2]}$ Especially $\mathrm{ZrB}_{2} /$ $\mathrm{SiC}$ and $\mathrm{HfB}_{2} / \mathrm{SiC}$ (with ca. 20 vol\% $\mathrm{SiC}$ ) composites have been reported to exhibit promising environmental behavior at UHTs, as they form a protective borosilicate glass coating. ${ }^{[13,14]}$ Moreover, intense efforts were made to further improve the environmental stability of SiC-modified diboride-based UHTCs by increasing the viscosity of the liquid silica-based layer, improving the immiscibility of multi-phasic liquid layers formed during oxidation process. ${ }^{[15]}$

\subsection{Thermodynamic Considerations and Solid-State Synthetic Approaches for UHTCs}

\subsubsection{Borides}

The excellent thermal stability as well as high hardness of group 4 transition metal diborides rely on their crystalline structure. They exist in a primitive hexagonal crystal structure $\left(\mathrm{AlB}_{2}\right.$-type, space group $P 6 / \mathrm{mmm}$ ) with two-dimensional graphene-like boron layers alternating with hexagonally close-packed metal layers. Thus, the extremely robust $\mathrm{B}-\mathrm{B}$ and $\mathrm{M}-\mathrm{B}$ bonds in $\mathrm{MB}_{2}$ $(\mathrm{M} 1 / 4 \mathrm{Zr}$, Hf) are naturally responsible for their ultra-high refractoriness and hardness (Table 1). Accordingly, $\mathrm{ZrB}_{2}$ and $\mathrm{HfB}_{2}$ exhibit extremely high melting temperatures (3245 and $3380{ }^{\circ} \mathrm{C}$, respectively) and the highest hardness values among their periods (23 and $28 \mathrm{GPa}$, respectively). ${ }^{[13,16,17]}$

In contrast to rocksalt nitrides and carbides, diborides have little variation in stoichiomentry and are essentially line compounds (see Figure $1 \mathrm{a}$ as for the Ti-B system ${ }^{[18]}$ ). Diborides of $\mathrm{Ti}, \mathrm{Zr}$, and $\mathrm{Hf}$ are the highest melting borides; however, in the Ta-B system (Figure 1b), ${ }^{[19,20]}$ the monoboride $\mathrm{TaB}$ has a marginally higher melting temperature than that of the
Table 1. Some physical and structural properties of $\mathrm{ZrB}_{2}$ and $\mathrm{HfB}_{2}$ (adapted from ref. [13]).

\begin{tabular}{ccccccc}
\hline & $\begin{array}{c}\text { Density } \\
{\left[\mathrm{gcm}^{-3}\right]}\end{array}$ & $\begin{array}{c}\text { Melting } \\
\text { point } \\
{\left[{ }^{\circ} \mathrm{C}\right]}\end{array}$ & $\begin{array}{c}\text { CTE } \\
{[\mathrm{ppm}} \\
\left.\mathrm{K}^{-1}\right]\end{array}$ & $\begin{array}{c}\text { Thermal } \\
\text { conductivity } \\
{[\mathrm{W} /(\mathrm{m} \mathrm{K})]}\end{array}$ & $\begin{array}{c}\text { Hardness } \\
{[\mathrm{GPa}]}\end{array}$ & $\begin{array}{c}\text { Young's } \\
\text { modulus } \\
{[\mathrm{GPa}]}\end{array}$ \\
\hline $\mathrm{ZrB}_{2}$ & 6.2 & 3245 & 5.9 & 60 & 23 & 489 \\
$\mathrm{HfB}_{2}$ & 11.2 & 3380 & 6.3 & 104 & 28 & 480 \\
\hline
\end{tabular}

corresponding diboride $\mathrm{TaB}_{2}(3363$ I5 $\mathrm{K}$ for $\mathrm{TaB}$ vs. 3310 To for $\mathrm{TaB}_{2}$ ). TaB is not found in NaCl-type structure, but possesses an orthorombic CrB-type $(\mathrm{Cmcm})$ structure. ${ }^{[21]}$ The monoboride of $\mathrm{Zr}$ was reported ${ }^{[22]}$ in $\mathrm{NaCl}$ structure, but it is only stable in a narrow temperature range below $1500 \mathrm{~K}$.

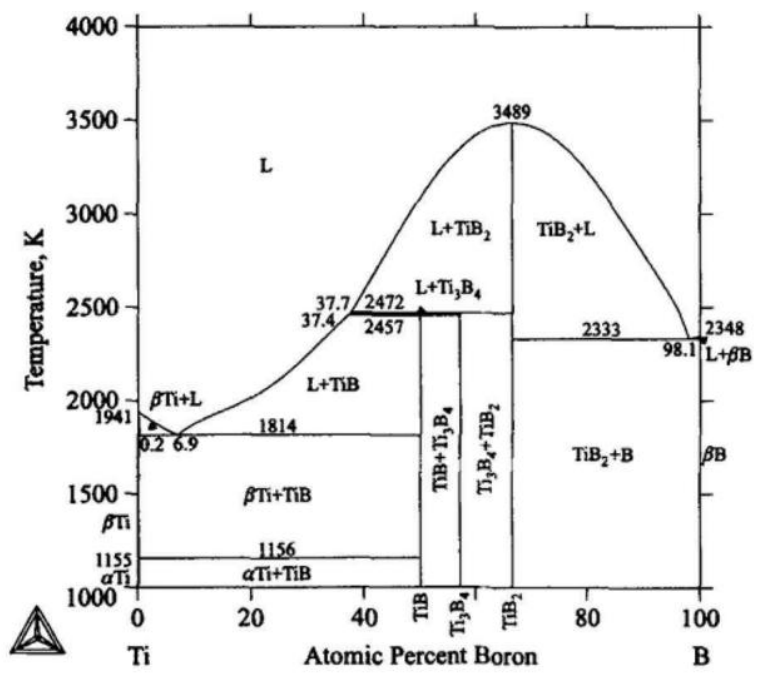

a)

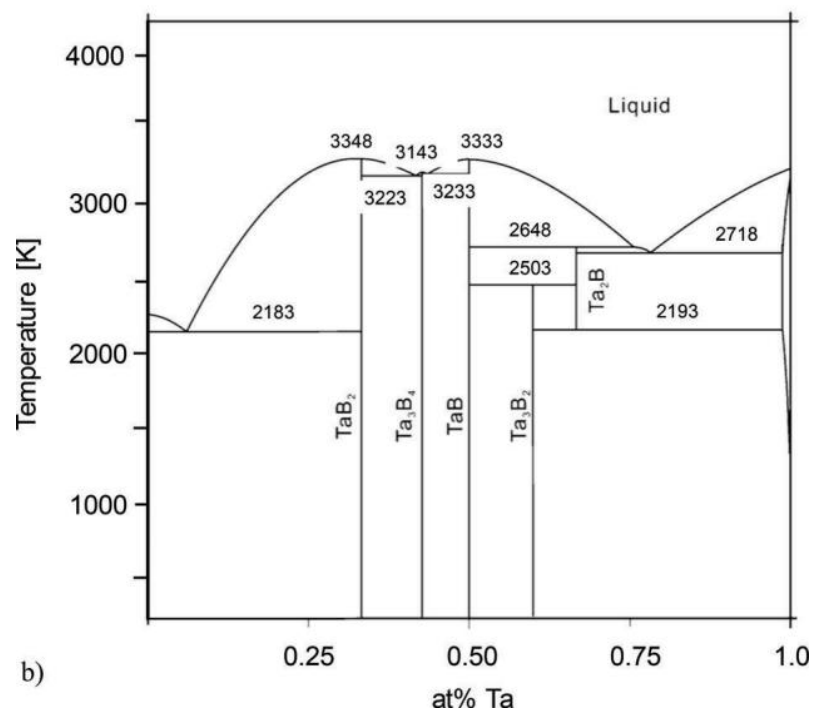

Figure 1. Phase diagrams of a) Ti-B (http://www.calphad.com/titaniumboron.html) and b) Ta-B systems. Reproduced with permission. ${ }^{[2]}$ Copyright, Elsevier. 
Over the last decade, multiple groups studied the thermodynamic properties of $\mathrm{ZrB}_{2}$ and $\mathrm{HfB}_{2}{ }^{[23,24]}$ Lawson et al. analyzed in detail the bonding situation in $\mathrm{ZrB}_{2}$ and $\mathrm{HfB}_{2}{ }^{[23]}$ and concluded that covalent bonding provides cohesion between boron atoms, while metallic bonding persists within the metal layer. A substantial charge transfer from the metal layer to the boron layer yields to strong ionic bonding between layers and is responsible for the substantial refractory character. Zhang et al. recently reported the remarkable structural stability of $\mathrm{ZrB}_{2}{ }^{\left[{ }^{[25]}\right.}$ Even when subjected to extreme pressures, the hexagonal structure remains the only competitive modification of the diboride. Further $\mathrm{Zr}-\mathrm{B}$ compounds have been investigated as well. Without doubt, $\mathrm{ZrB}$ in the rocksalt structure is mechanically stable. ${ }^{[26]}$ However, computed lattice parameters do not agree with experimental data within the usual tolerances of firstprinciples calculations. Further mechanically and dynamically stable structures are $\mathrm{Zr}_{3} \mathrm{~B}_{2}, \mathrm{Zr}_{3} \mathrm{~B}_{4}, \mathrm{Zr}_{2} \mathrm{~B}_{3}, \mathrm{ZrB}_{2}$, and $\mathrm{ZrB}_{12}$. ${ }^{\text {[27] }}$ Only $\mathrm{ZrB}_{2}$ appears to be thermochemically stable, and results for $\mathrm{ZrB}_{12}$ are still undecided. ${ }^{[2]}$ However, a mononitride $\mathrm{ZrB}$ appears as the least competitive phase, and the rocksalt type of $\mathrm{ZrB}$ is less favorable than an orthorhombic modification. This, furthermore, suggests that the observed rocksalt-type may either be defect-rich or even stabilized by carbon. Noteworthy in this context is the work of Lee et al., who identified insertion of boron into octahedral sites of the hcp Zr structure as energetically most favorable. ${ }^{[29]}$

The thermochemistry of $\mathrm{Hf}-\mathrm{B}$ compounds is very similar to those in the $\mathrm{Zr}-\mathrm{B}$ system. $\mathrm{HfB}_{2}$ dominates the phase diagram, with orthorhombic $\mathrm{HfB}$ and $\mathrm{HfB}_{12}$ competitive but not favored by enthalpy. ${ }^{[28,30]}$

The Ta-B system shows more diversity than borides of $\mathrm{Zr}$ and $\mathrm{Hf}$ (see Figure $1 \mathrm{~b}$ ). With exception of the well-known $\mathrm{AlB}_{2}$-type of $\mathrm{TaB}_{2}$, all appearing structures are quite complex thanks to prevalent Ta-Tabonding. Boron-rich phases exhibit fragments of the $\mathrm{TaB}_{2}$ structure, e.g., a one-dimensional strip of condensed $\mathrm{B}_{6}$-rings, interrupted by additional Ta atom. Tantalum-rich structures display motifs of dense packings with B atoms filling interstitial sites, however, with significant distortions. Calculations indicate that $\mathrm{Ta}_{3} \mathrm{~B}_{2}, \mathrm{TaB}, \mathrm{Ta}_{5} \mathrm{~B}_{6}, \mathrm{Ta}_{3} \mathrm{~B}_{4}, \mathrm{Ta}_{2} \mathrm{~B}_{3}$, and $\mathrm{TaB}_{2}$ are thermochemically stable. ${ }^{[28]}$

Diboride-based UHTCs can be synthesized by different approaches. Most of them rely on reduction processes of the oxides (zirconia, hafnia, boria). Carbon and boron are the most used reducing agents. The carbothermal process has been the mostly used technique to produce diborides and involves the reaction of a mixture consisting of metal oxide (i.e., $\mathrm{ZrO}_{2}$ or $\mathrm{HfO}_{2}$ ) and $\mathrm{B}_{2} \mathrm{O}_{3}$ with carbon. As these processes are strongly endothermic, temperatures of synthesis typically around $2000{ }^{\circ} \mathrm{C}$ are needed. ${ }^{[11]}$ Usually, boria is added in excess in order to promote the formation of the diborides and to inhibit carbide formation. Common impurities in carbothermally synthesized diboride powders are carbon, boria, and metal carbides. $^{[11,13]}$

The reaction of the group 4 transition metal oxides with boron (borothermic reaction) as well as aluminothermic processes $\left(\mathrm{MO}_{2}\right.$ and boria reacting with $\left.\mathrm{Al}\right)$ are also strongly endothermic and are performed at temperatures exceeding 1400-1500 ${ }^{\circ} \mathrm{C} .{ }^{[1]}$ The reduction of the metal oxides with boron carbide $\left(\mathrm{B}_{4} \mathrm{C}\right)$ was shown to become thermodynamically favorable at temperatures as low as $1200{ }^{\circ} \mathrm{C}$. An additional advantage of the reduction process with $\mathrm{B}_{4} \mathrm{C}$ relies on the reduced amounts of carbon and oxide impurities in the synthesized diboride powders. ${ }^{[31,32]}$

Group 4 transition metal diborides (as well as other transition metal borides) can also be synthesized from elements. Depending on the purity of the starting materials, diborides of high purity are accessible upon this process. However, due to the poor oxidation resistance of the group 4 transition metals, these processes have to be performed in inert atmosphere in order to avoid the formation of the corresponding metal oxides. As the reactions of $\mathrm{Zr}$ and $\mathrm{Hf}$ with $\mathrm{B}$ are highly exothermic, ${ }^{[1]}$ self-propagating high-temperature synthesis (SHS) techniques have been developed to prepare diboride powders from elements. ${ }^{[33,34]}$

Table 2 summarizes best available values for melting temperatures, standard entropies, and enthalpies of formation at $298 \mathrm{~K}$ for selected borides, carbides, and nitrides of $\mathrm{Ti}, \mathrm{Zr}, \mathrm{Hf}$, and Ta. The data for corresponding oxides are included for comparison. The data referenced to NIST-JANAF and Glushko's thermochemical tables are largely based on the evaluation of measurements performed before 1970. Formation enthalpies for $\mathrm{TiC}, \mathrm{TaB}_{2}$, and $\mathrm{TiB}_{2}$ are given after more recent calorimetry measurements performed in Kleppa's group. ${ }^{[35,36]}$ The uncertainties are given when provided in the original reference.

Synthetic approaches using reactive processes have also been applied to the preparation of diboride-silicon carbide composite materials. Thus, hot-pressing of a mixture of metallic zirconium, carbon, and silicon tetraboride, $\mathrm{SiB}_{4}$, led to monolithic $\mathrm{ZrB}_{2} / \mathrm{SiC}$ composites. A small amount of $\mathrm{ZrC}$ impurity has been also detected. ${ }^{[50]}$

Reactive hot-pressing of a powder mixture containing zirconium, boron carbide $\mathrm{B}_{4} \mathrm{C}$, and silicon was also used to prepare $\mathrm{ZrB}_{2} / \mathrm{SiC}$ monoliths with high densities at a temperature as low as $1900{ }^{\circ} \mathrm{C} .{ }^{[51]}$

\subsubsection{Carbides and Nitrides}

Generally, transition metal carbides, nitrides, and carbonitrides represent a unique class of materials with outstanding structural

Table 3. Selected physical and structural properties at room temperature of stoichiometric group 4 transition metal carbides and nitrides (i.e., composition near to 50 at\% metal).

\begin{tabular}{lcccc}
\hline & $\mathrm{ZrC}$ & $\mathrm{HfC}$ & $\mathrm{ZrN}$ & $\mathrm{HfN}$ \\
\hline Density $\left[\mathrm{g} \mathrm{cm}^{-3}\right.$ ] & 6.5 & 12.3 & 7.3 & 13.8 \\
Melting point $\left[{ }^{\circ} \mathrm{C}\right]$ & 3420 & 3930 & 3000 & 3330 \\
$\mathrm{CTE}\left[\mathrm{ppm} \mathrm{K} \mathrm{K}^{-1}\right]$ & 7.5 & 6.1 & 7.8 & 8.5 \\
Th. conductivity $[\mathrm{W} /(\mathrm{m} \mathrm{K})]$ & 24.6 & 25.1 & 11 & 11 \\
Hardness [GPa] & 25 & 20 & 15 & 18 \\
Young's modulus [GPa] & 350 & 420 & 460 & 380 \\
Electrical resistivity $[\mathrm{m} \Omega \mathrm{cm}]$ & 75 & 67 & 24 & 27 \\
Curie temperature, $T_{\mathrm{c}}[\mathrm{K}]$ & - & - & 10.47 & 6.92 \\
\hline
\end{tabular}

Data taken from ref. [52]. 
properties, such as very high melting points, exceptional high hardness, or high-temperature ablation resistance. ${ }^{[52]}$ Furthermore, they exhibit metallic character with respect to electrical and thermal conductivities, fascinating surface properties, and interesting catalytic behavior. In particular, group 4 transition metal carbides and nitrides have been shown to exist over broad ranges of composition with an upper limit to $\mathrm{C}: \mathrm{M}$ or $\mathrm{N}: \mathrm{M}$ ratio close to unity. They exhibit tremendous thermal stability (e.g., group 4 transition metal nitrides can melt without suffering decomposition, unlike groups 5 or 6 transition metal nitrides), which has been shown to rely on their free energy of formation. $^{\text {[52] }}$

Group 4 carbides and nitrides belong to the class of interstitial compounds, having as characteristics simple metallic lattices (face-centered cubic, fcc) and carbon or nitrogen atoms located in their octahedral interstitial sites. Their bonding is characterized by a mixture of metallic, ionic, and covalent components. With respect to thermal or electronic transport, carbides and nitrides of group 4 transition metals exhibit metallic behavior. As the carbides show lower density of state (DOS) at the Fermi level than the corresponding nitrides, the electrical and thermal conductivity as well as the $T_{\mathrm{c}}$ values of the group 4 carbides are lower than those of the analogous nitrides. ${ }^{\text {[52] }}$

Transition metal carbides are known for their extremely high melting points (Table 3). For instance, $\mathrm{ZrC}$ shows a congruent melting point of $3420{ }^{\circ} \mathrm{C}$, whereas HfC melts congruently at $3930{ }^{\circ} \mathrm{C}$. The material predicted to have the highest known melting point $\left(4215^{\circ} \mathrm{C}\right)$ is a solid solution of $\mathrm{HfC}$ and $\mathrm{TaC}$ in a molar ratio $4: 1$, with a composition of $\mathrm{Ta}_{4} \mathrm{HfC}_{5}$ (compare to the melting point of $\mathrm{TaC}, 3985{ }^{\circ} \mathrm{C}$ ). Also, transition metal nitrides have extremely high melting points, often above $3000{ }^{\circ} \mathrm{C}(\mathrm{TiN}$ : $3030{ }^{\circ} \mathrm{C} ; \mathrm{ZrN} 3000{ }^{\circ} \mathrm{C}$; HfN $3330{ }^{\circ} \mathrm{C}$ ).

Table 2. Standard entropies, enthalpies of formation, and melting temperatures for selected borides, carbides; and nitrides of $\mathrm{Ti}, \mathrm{Zr}, \mathrm{Hf}$, and Ta.

\begin{tabular}{|c|c|c|c|}
\hline Compound & $\Delta \mathrm{H}^{\circ} \mathrm{f}_{298.15}\left[\mathrm{~kJ} \mathrm{~mol}^{-1}\right]$ & $\mathrm{S}_{298.15}^{\circ}\left[\mathrm{Jmol}^{-1} \mathrm{~K}^{-1}\right]$ & $T_{\mathrm{m}}\left[{ }^{\circ} \mathrm{C}\right]$ \\
\hline TiC & $-186 \mathrm{~T} 18^{[35]}$ & $24.7 \mathrm{~T} 0.2^{[37]}$ & $3067 \mathrm{~T} 25^{[37]}$ \\
\hline $\mathrm{TiB}_{2}$ & $-328 \mathrm{~T} 10^{[36]}$ & $28.9 \mathrm{~T} 0.4^{[37]}$ & $3225 \mathrm{~T} 25^{[38,39]}$ \\
\hline TiN & $-338 \mathrm{~T} 4^{[40]}$ & $30.3 T 0.2^{[40]}$ & $2945 T 30^{[41]}$ \\
\hline $\mathrm{TiO}_{2}$ & $-944 \mathrm{~T} 1[37]$ & $50.3 \mathrm{~T} 0.2\{37]$ & $1870 \mathrm{~T} 155_{37]}$ \\
\hline $\mathrm{ZrC}$ & $-207 \mathrm{~T} 3^{[37]}$ & $33.3 \mathrm{~T} 0.1^{[37]}$ & $3572 \mathrm{~T} 30^{[42]}$ \\
\hline $\mathrm{ZrB}_{2}$ & $-323 T 7^{[40]}$ & $35.9 T 0.1^{[40]}$ & $3244^{[43]}$ \\
\hline $\mathrm{ZrN}$ & $-342^{[44]}$ & $38.9 T 0.2^{[37]}$ & $2955 \mathrm{~T} 30^{[41]}$ \\
\hline $\mathrm{ZrO}_{2}$ & $-1101 \mathrm{~T} 1^{[37]}$ & $50.4 \mathrm{~T} 0.4^{[37]}$ & $2710^{[45]}$ \\
\hline $\mathrm{HfC}$ & $-208 T 8^{[37]}$ & $40.1 \mathrm{~T} 0.2^{[37]}$ & $3982 \mathrm{~T} 30^{[42]}$ \\
\hline $\mathrm{HfB}_{2}$ & $-329 \mathrm{~T} 9^{[46]}$ & $42.6^{[37]}$ & $3378 \mathrm{~T} 20^{[22]}$ \\
\hline $\mathrm{HfN}$ & $-374 \mathrm{~T} 2^{[37]}$ & $45 \mathrm{~T} 1^{[37]}$ & $3330 \mathrm{~T} 50^{[41]}$ \\
\hline $\mathrm{HfO}_{2}$ & $-1118 \mathrm{~T}^{[37]}$ & $59.3 \mathrm{~T} 0.6^{[37]}$ & $2800^{[45]}$ \\
\hline $\begin{array}{l}\mathrm{TaC} \\
\mathrm{TaB} \\
{ }_{2}\end{array}$ & $\begin{array}{l}-142 \mathrm{~T} 3^{[37]} \\
-^{160} \mathrm{~T}^{6[47]}\end{array}$ & $\begin{array}{c}42.3 \mathrm{~T} 0.2^{[37]} \\
47 \mathrm{~T} 4^{[37]}\end{array}$ & $\begin{array}{l}4003 \mathrm{~T} 30^{[42]} \\
3037 \mathrm{~T} 20^{[48]}\end{array}$ \\
\hline $\mathrm{TaN}$ & $-252 \mathrm{~T} 2^{[49]}$ & $41.8 \mathrm{~T} 1.2^{[49]}$ & †2930T30 ${ }^{[41]}$ \\
\hline $\mathrm{TaO}_{2.5}$ & $-1024 \mathrm{~T} 1^{[37]}$ & $71 \mathrm{~T} 1^{[37]}$ & $1872 \mathrm{~T} 10^{[37]}$ \\
\hline
\end{tabular}

Group 4 transition metal carbides can be prepared from elements as well. As the reactions are strongly exothermic, SHS techniques can be used to synthesize carbide powders. Transition metal nitrides can be produced similarly. ${ }^{[53]}$ Carbides can also be synthesized by reduction of oxides with carbon at high temperatures. Thus, zirconia or hafnia powders can be reacted with carbon at temperatures as low as $1600{ }^{\circ} \mathrm{C}$ to prepare fine and ultrafine carbide powders. ${ }^{[54-58]}$ Due to their high sinter activity (and to some extent to small oxygen impurities), they can be densified at relatively low temperatures. The carbothermal process was combined with the SPS technique to prepare monolithic zirconium and hafnium carbides. ${ }^{[59]}$

The corresponding bulk nitrides can be prepared from group 4 transition metals or metal hydrides via heat treatment in nitrogen or ammonia atmosphere. Carbo-nitridation of metal oxides at high temperatures also furnishes metal nitrides (which contain oxygen and carbon impurities). ${ }^{[52]}$

Except for TaN, all compounds listed in Table 2 are reported to melt congruently. TaN decomposes to $\mathrm{Ta}_{2} \mathrm{~N}$ which has a slightly higher melting temperature $(3232 \mathrm{~K})$. It is not uncommon to find discrepancies of a hundred degrees or more in melting temperatures between different reports, especially for borides and nitrides. Melting temperatures of nitrides are reported after measurements by Ettmayer et al., ${ }^{[41]}$ which are the average from experiments performed at 1-80 atm nitrogen pressure.

$\mathrm{Ti}, \mathrm{Zr}, \mathrm{Hf}$, and Ta carbides and nitrides are found in $\mathrm{NaCl}$ (rocksalt) structure, in whichs the metal forms a cubic closepacked lattice and $\mathrm{C}$ or $\mathrm{N}$ fill some or all octahedral sites comprising from 35 to 50 at\%. These compounds possess high electrical conductivities. They are sometimes referred to as $\delta$ phase $^{[60]}$ or interstitial phases ${ }^{[61]}$ referring to intercalation of $f c c$ metal lattice with $\mathrm{C}$ or $\mathrm{N}$.

Complete miscibility can be found among $\mathrm{Ti}, \mathrm{Zr}$, Hf, Ta carbides and nitrides at high tempeatures (ca. $2000{ }^{\circ} \mathrm{C}$ ). The stability of these solid solutions and exact temperatures and shapes of miscibility gaps depend on vacancies concentrations. ${ }^{[62]}$ From the analysis of phase diagrams, the congurently melting compositions for rock salt carbides and nitrides deviate from ideal stoichiometry with $44-48$ at $\%$ of nonmetal.

Yu et al. investigated several structures in the Ta-C system and showed the elasticity of $\mathrm{TaC}_{1-x}$ decreases with loss of carbon in the structure, which is related to a decrease in covalent bonding between $\mathrm{Ta}$ and $\mathrm{C}$ paralleled by an increase in metallic

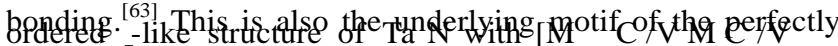

\section{$\left.1 / 4 \frac{1}{4} \mathrm{M}_{3} \mathrm{C}_{2}\right]$}

$$
\zeta
$$

An interesting topic are mixtures of metal carbides forming UHTCs. Not only is the enthalpy of mixing relevant to stability of phases, but also a potential mixing entropy among the metal cations. Vorotilo et al. investigated solid-solutions of $\mathrm{TaC}$ and $\mathrm{ZrC}$ in the rocksalt structure with full occupation of cation and anion positions. ${ }^{[64]}$ Computed lattice parameters and bulk moduli of solid solutions follow a rule of mixture and agree with experimental data. The enthalpy of mixing $\Delta H$ of intermediate compositions $\mathrm{Ta}_{x} \mathrm{Zr}_{1-x} \mathrm{C}$ is negative for all $x$ with a maximum $\Delta H^{1 / 4}-0.030 \mathrm{eV}$ atom ${ }^{1}$ at $x_{4}^{1 / 4} 0.625$. Experimental work carried out in parallel did not indicate decomposition of solid solution, suggesting complete solubility without miscibility gap in the $\mathrm{Ta}_{x} \mathrm{Zr}_{1-x} \mathrm{C}$ phase diagram. 
The Hf-N system (see phase diagram in Figure 2a ${ }^{[65]}$ ) displays several compounds favored by enthalpy. Two recent comprehensive studies present structures and thermochemistry in this system using DFT calculations. ${ }^{[66,67]}$ Besides HfN, structures of compositions $\mathrm{Hf}_{4} \mathrm{~N}_{3}, \mathrm{Hf}_{3} \mathrm{~N}_{2}, \mathrm{Hf}_{2} \mathrm{~N}, \mathrm{Hf}_{3} \mathrm{~N}, \mathrm{Hf}_{6} \mathrm{~N}$, and, probably,

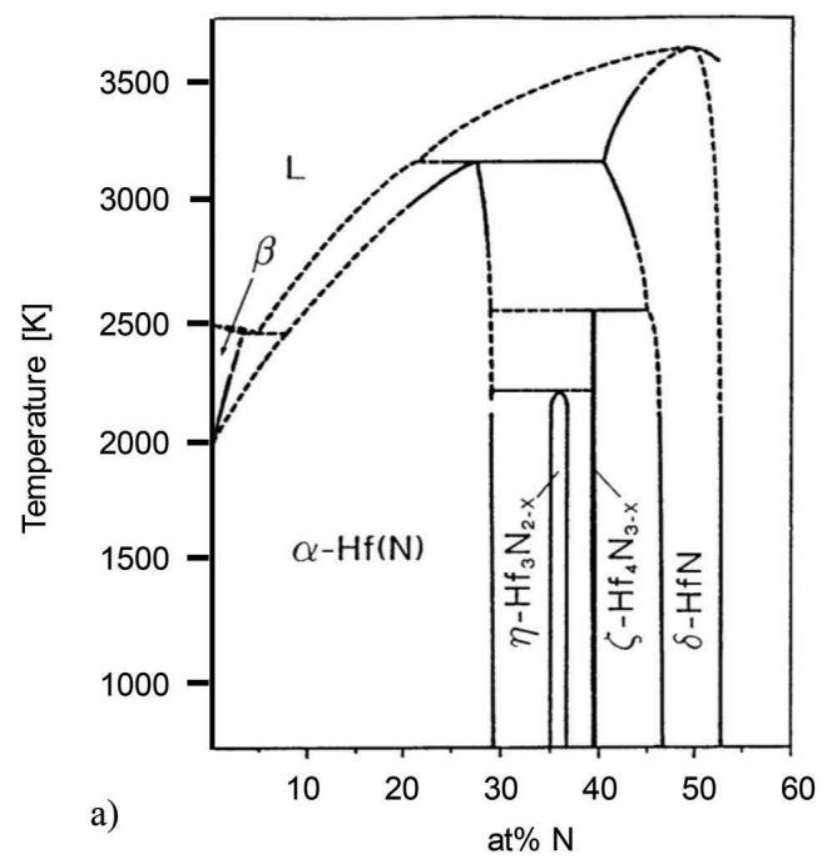

\section{HfN}
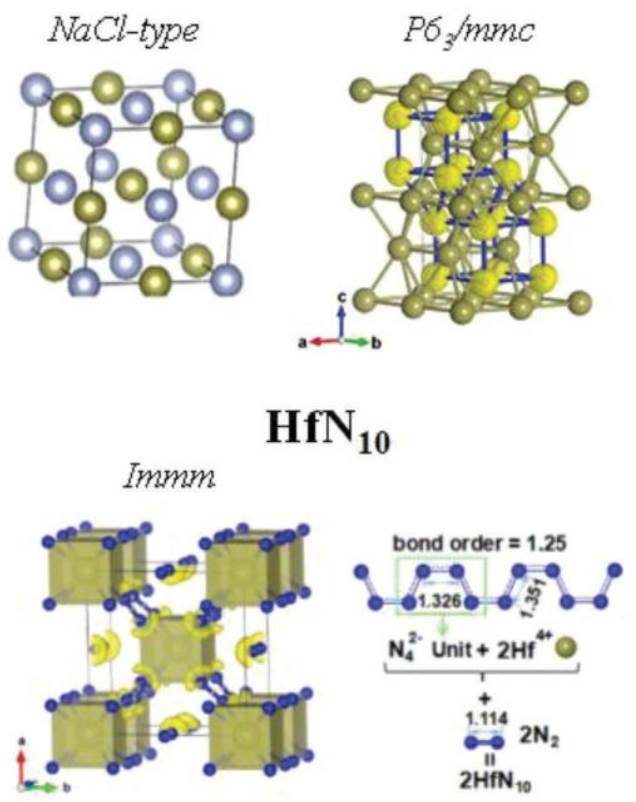

b)

Figure 2. a) Phase diagram of the $\mathrm{Hf}-\mathrm{N}$ system (Reproduced with permission. ${ }^{[65]}$ Copyright, Springer); b) crystalline structures of HfN ( NaCl-type and $\mathrm{P} 6_{3} / \mathrm{mmc}$ ) and of $\mathrm{HfN}_{10}(\mathrm{Immm})$. For $/ \mathrm{mmm}-\mathrm{HfN}_{10}$, infinite polymeric nitrogen chains and $N_{-} \mathrm{N}$ bondings are shown (Reproduced with permission. ${ }^{[67]}$ Copyright, American Physical Society).
$\mathrm{Hf}_{8} \mathrm{~N}$ appear thermochemically stable towards the metal-rich side of the phase diagram. All structures can be described as being related to densest packings of metal atoms with $\mathrm{N}$ filling octahedral interstitials. Surprisingly, a new polymorph of HfN with hexagonal structure $\left(\mathrm{PC}_{3} / \mathrm{mmc}\right.$; Figure $\left.2 \mathrm{~b}\right)$ was discovered to be the most favorable modification of HfN ${ }^{\text {[67] }}$ Careful work indicated that the rocksalt type of HfN (Figure 2b), previously assumed to be dominant, only becomes thermodynamically stable above $670{ }^{\circ} \mathrm{C}$. Metal cations in hexagonal $P \sigma_{3} / m m c$-HfN fall onto the sites of the La structure type, a simple intergrowth of $h c p$ and $c c p$ with repetition every four layers, also termed double hexagonal closest packing (dhcp). Anions fill all octahedral sites, giving the hexagonal HfN structure the flavor of NiAs-type and rocksalt type joined together. Toward the nitrogen-rich side of the phase diagram structures with composition $\mathrm{Hf}_{11} \mathrm{~N}_{12}, \mathrm{Hf}_{7} \mathrm{~N}_{8}$ and $\mathrm{Hf}_{4} \mathrm{~N}_{5}$ appear, all described as cation-deficient rock-salt structures. Besides the high-pressure phase $\mathrm{Hf}_{3} \mathrm{~N}_{4}$ with $\mathrm{Th}_{3} \mathrm{P}_{4^{-}}$ type structure, ${ }^{[60]}$ the most nitrogen-rich compound of $\mathrm{Hf}$ thermochemically stable at ambient pressure is $\mathrm{Hf}_{3} \mathrm{~N}_{4}$, for which a new monoclinic structure has been proposed. ${ }^{[67]}$ At pressures beyond $23 \mathrm{GPa}$, an $\mathrm{Immm}$ - $\mathrm{HfN}_{10}$ phase was predicted via DFTcalculations and exhibits Hf atoms eightfold coordinated by nitrogen and consists of infinite polymeric nitrogen chains ( $\mathrm{N}-\mathrm{N}$ bond has a bond order of 1.25 ) and encapsulated $\mathrm{N}-\mathrm{N}$ molecular units (Figure 2b).

Calculations of the $\mathrm{Ta}-\mathrm{N}$ system do not yield as many thermochemically stable structures as the Hf-N system. $\mathrm{Ta}_{3} \mathrm{~N}_{5}$, which can be synthesized, appears together with $\mathrm{Ta}_{2} \mathrm{~N}_{3}$ as nitrogen rich phases in the phase diagram at low temperatures. It is well known, however, that upon annealing to $1000{ }^{\circ} \mathrm{C}$, $\mathrm{Ta}_{3} \mathrm{~N}_{5}$ decomposes through a series of phases of intermediate composition into TaN. The phase diagram (Figure 3a ${ }^{[68,69]}$ ) is then dominated by $\mathrm{e}-\mathrm{TaN}^{[70-72]}$ with a hexagonal structure related to the intermetallic CoSb (Figure 3b). Ta atoms form dense packed layers which are tightly stacked similar to a hexagonal closest packing. With the shorter stacking distance, Ta-Ta bonds persist between next-nearest layers. Anions are then located within the plane of every other Ta layer and do not occupy interstitial sites (Figure $3 b$ ). In comparison to rocksalttype TaN, e-TaN has a major energy advantage, but lacks a similar defect chemistry. The next stable phase then is $\mathrm{Ta}_{2} \mathrm{~N}$, which structure is best described as a hexagonal closest packing of Ta with $\mathrm{N}$ filling octahedral sites in every other layer (Figure 3b). Although the metal arrangements in both e-TaN and $\mathrm{Ta}_{2} \mathrm{~N}$ are described in similar terms, intermediate structures with anion deficiency do not appear with competitive enthalpy of formation. ${ }^{[66]}$

It is worthy to mention that first-principles calculations of thermochemistry for nitride UHTCs face a tough challenge. Reaction enthalpies are computed at 0 Kelvin. Entropy differences between reactants and products are often neglected, and enthalpy differences are assumed to remain constant over the range of temperatures. Even if those differences are taken into consideration and there are some fine works that go the extra mile ${ }^{[67]}$ - such an approach is impossible for nitrogen. $\mathrm{N}$ is a gaseous molecule at ambient conditions, quite unlike elemental $\mathrm{B}$ and $\mathrm{C}$, which are solid-state compounds. Being a gas, both enthalpy and entropy of nitrogen change significantly larger with increasing temperature than those of the solids, and the 

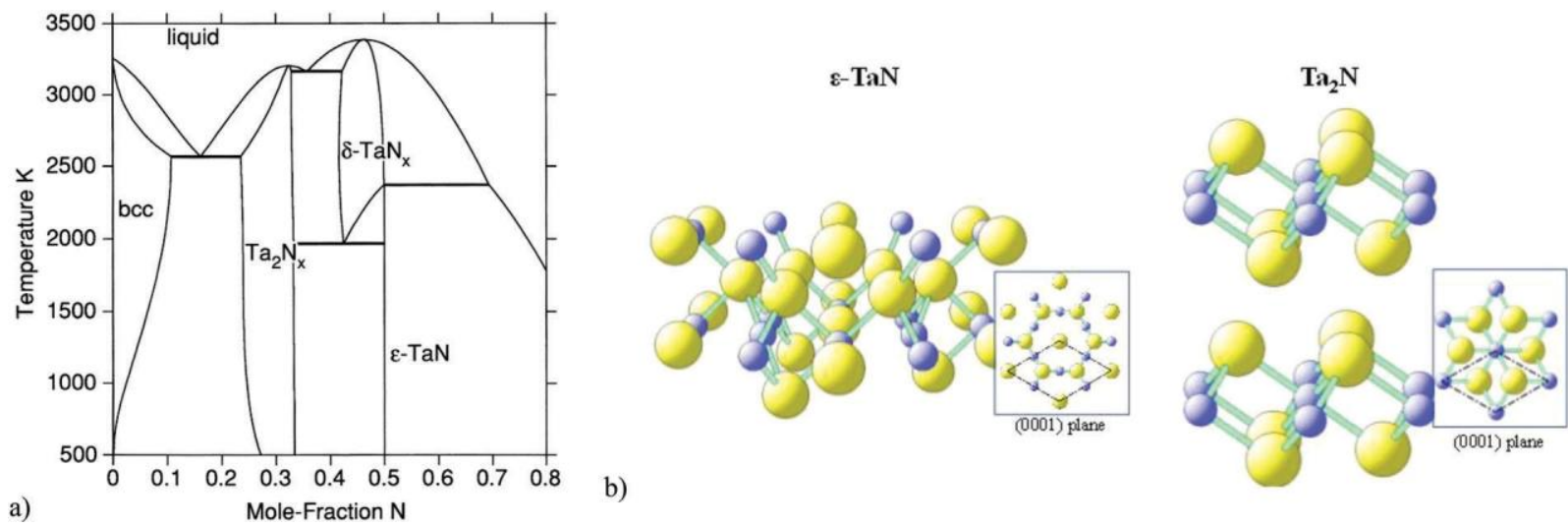

Figure 3. a) Phase diagram of the Ta-N system ${ }^{[68,69]}$ (Reproduced with permission. ${ }^{[69]}$ Copyright, Springer); b) crystalline structures of e-TaN (P6/ $\mathrm{mmm})$ and $\mathrm{Ta}_{2} \mathrm{~N}(\bar{P} \overline{\mathrm{ml}}): \mathrm{N}$ and Ta: blue and yellow spheres, respectively; dashed lines in the insets indicate the cell unit (Reproduced with permission. ${ }^{[72]}$ Copyright, American Physical Society).

computational arsenal to assess heat capacity and vibrational entropy loses its strength. Consequently, one cannot hope for fortuitous error cancellation in reaction enthalpies between products and reactants. This sets $\mathrm{N}$ apart from $\mathrm{B}$ and $\mathrm{C}$, and makes incorporation of the chemical potential of nitrogen at elevated temperatures indispensable for predicting nitride phases. ${ }^{[73-75]}$

Standard enthalpies of formation are the least negative for carbides and most negative for oxides. This does not reflect the bond strength in compounds, but is mainly related to the difference in the reference states for nonmetal atoms, which are $\mathrm{N}_{2}, \mathrm{O}_{2}$, and graphite. Formation enthalpies show that carbides, nitrides, andborides are expected tobe unstable to oxidation. For $\mathrm{Zr}$, Hf, and Ta, melting temperatures decrease in the order of carbides - borides - nitrides - oxides, spannnig a range of $1-$ 2000 degrees. Titanium diboride is an exception from this trend, with its melting temperature $(3498 \mathrm{~K})$ exceeding that of $\mathrm{TiC}$ (3340 K).

No experimental measurements of fusion enthalpies for $\mathrm{Ti}, \mathrm{Zr}, \mathrm{Hf}$, and Ta carbides, borides and nitrides have been reported. First principles computations are increasingly used to evaluate thermodynamic properties of these compounds: thermal expansion and heat capacities were computed for $\mathrm{ZrC}$ and $\mathrm{ZrN}$ up to $3000-\mathrm{K}^{[76]}$ and the effect of carbon vacancies on miscibility gap in $\mathrm{TiC}-\mathrm{ZrC}$ carbides was analyzed, ${ }^{[62]}$ and melting temperatures were studied in the Hf-C-N system. ${ }^{[77]}$

Since carbides, borides, and nitrides of transition metals are good electrical conductors, most of the measurements of their melting temperatures were performed by direct bulk heating of the samples with electric current using an experimental arrangement known as Pirany furnace. In this method, first used by Pirany and Alterthum in $1923,{ }^{[78]}$ the melting occurs in the bottom of the blind hole drilled in the test specimen. The hole also serves as black body cavity to aim pyrometer for the temperature measurements, eliminating the uncertainty from sample emissivity. This arrangement was used by Rudy et al. ${ }^{[79]}$ on carbides and borides and by Ettmayer ${ }^{[41]}$ to study nitrides. For metals which can be drawn as a wire, the Joule heating evolved into exploding wire technique, which now also yields enthalpy as a function of temperature in the solid and liquid state. ${ }^{[80]}$

For almost 40 years no new studies on melting temperatures of carbides, borides, and nitrides by Joule heating method have been performed; however, the renewed interest in refractory carbides for UHTCs resulted in a new surge of experimental efforts. Pulsed laser melting technique, originally developed for refractory oxides, was recently applied to study the melting of Ta, $\mathrm{Hf}$, and $\mathrm{Zr}$ carbides. ${ }^{[42,81]}$ In this method, melting is induced by millisecond laser pulses, the surface temperature is recorded with a fast spectropyrometer and liquidus and solidus temperatures are derived from thermal arrests on cooling. Pulsed laser measurements of HfC melting point performed by Barraza et al. ${ }^{[81]}$ in Germany $\left(3959784^{\circ} \mathrm{C}\right)$ and by Sheindlin et al. ${ }^{[42]}$ in Russia $\left(3982 \mathrm{TBO}^{\circ} \mathrm{C}\right.$ ) are in reasonable agreement with each other and with earlier Pirany furnace measurements by Rudy et al. ${ }^{[79]}$ in California $\left(3928 \mathrm{TH0}^{\circ} \mathrm{C}\right)$. However, there is a large discrepancy for reported $\mathrm{TaC}$ melting point from pulsed laser measurements: $\left(3768 \mathrm{~B} \quad{ }^{\circ} \mathrm{C}\right)^{[81]}$ versus $\left(4003\right.$ $\left.30{ }^{\circ} \mathrm{C}\right) .{ }^{[42]}$ The higher value reported by Sheindlin et al. ${ }^{[42]}$ (and included in Table 2) is also consistent with earlier results from Pirany furnace $\left(3983 \mathrm{~T}^{\circ}{ }^{\circ} \mathrm{C}\right) .{ }^{[79]}$ Recently, a pulsed Joule heating technique was also used on $250 \mu \mathrm{m}$ thick carbide samples, ${ }^{[82,83]}$ to analyze melting temperature, heat capacity and fusion enthalpy for $\mathrm{Zr}$ carbide and nitride. ${ }^{[84,85]}$

The prize for highest melting solid was given to $\mathrm{Ta}_{0.8} \mathrm{Hf}_{0.2} \mathrm{C}$ in 1930 by Agte and Alterthum ${ }^{[86]}\left(=60{ }^{\circ} \mathrm{C}\right.$ higher than $\left.\mathrm{TaC}\right)$, in 1967 Rudy et al. ${ }^{[79]}$ gave it to $\mathrm{TaC}\left(3983^{\circ} \mathrm{C}\right)$. Both teams were using Pirany furnace. Barraza et al. ${ }^{[81]}$ gave it to HfC from laser pulse melting, and recent work using electric pulse method returns it back to $\mathrm{Ta}_{0.8} \mathrm{Hf}_{0.2} \mathrm{C}\left(4027{ }^{\circ} \mathrm{C}\right) .{ }^{[83]}$ However, computational work predict that experimentalists are looking in the wrong system and the highest melting solid is a $\mathrm{Hf}-\mathrm{C}-\mathrm{N}$ alloy ${ }^{[77]}$ (Figure 4).

There is much to be done in refining experimental measurements and synthesis, and characterization techniques and, for practical applications, oxidation behavior and properties of oxycarbides are more critical than absolute values of melting temperatures for pure compounds. 


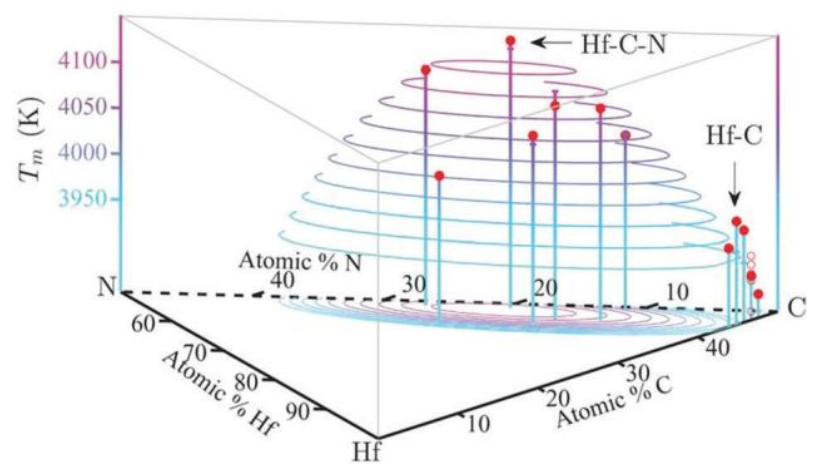

Figure 4. Melting temperatures of materials compositions in the $\mathrm{Hf}-\mathrm{C}-\mathrm{N}$ and $\mathrm{Hf}-\mathrm{C}$ (red filled circles) as well as $\mathrm{Hf}-\mathrm{Ta}-\mathrm{C}$ (empty circles) systems (Reproduced with permission. ${ }^{[77]}$ Copyright, American Physical Society).

\section{Ceramic Synthesis from Preceramic Polymers (the PDC Route) - A Brief Introduction}

Single-source preceramic precursors provide a facile and inexpensive access to various ceramic systems with tailored phase compositions, microstructures and property profiles. Among them, polymeric single-source precursors are of special relevance, as they can be used for the preparation of ceramic bulk powders, dense monoliths, macro, meso and micro porous bodies, thin films and coatings, miniaturized (microstructured) components, fibers, etc. Furthermore, polymeric single-source precursors allow preparation of unique ceramic compositions and microstructures, which are not accessible via other preparative techniques. The molecular structure and chemistry of the single-source precursors greatly influence the composition, microstructure, and phase distribution of the final ceramic product, providing the advantage to control and design ceramic materials with various macroscopic and physical properties. ${ }^{[87]}$ In this context, a crucial role is played by the synthesis of suitable precursors with tailored composition and molecular architecture. ${ }^{[87-89]}$

Polymer-based single-source precursors for the preparation of ceramic nanocomposites were taken into account in the $1980 \mathrm{~s},{ }^{[90,91]}$ as researchers started to look for appropriate synthesis techniques for nanoscale non-oxidic ceramics. However, already in the late 1950 s and 1960 s studies related to the conversion of molecular precursors into non-oxidic ceramics were reported ${ }^{[92-94]}$; furthermore, in the 1970s, polymeric precursors such as polycarbosilanes (PCS) or polysilazanes (PSZ) were used to prepare small-diameter $\mathrm{SiC}$ and $\mathrm{SiC} / \mathrm{Si}_{3} \mathrm{~N}_{4}$ ceramic fibers. ${ }^{[95,96]}$ These preparative efforts culminated in the commercialization of the Yajima production process of continuous $\mathrm{SiC}$ ceramic fibers. ${ }^{[96,97]}$ These $\mathrm{SiC}$ fibers were shown to exhibit excellent high temperature stability and promising mechanical properties. However, there are some limitations concerning their use at high temperatures, as they possess limited oxidation resistance and poor mechanical properties above $1300{ }^{\circ} \mathrm{C} .{ }^{[98,99]}$ In this context, numerous studies have been performed with respect to the modification of the SiCbased fibers with metals in order to improve their properties. Mainly, PCS was modified with metal alkoxides or acetyl acetonates (metal1//4i, $\mathrm{Zr}, \mathrm{Al}$, etc.). ${ }^{[100-102]}$ Depending on the metal precursor used for the chemical modification, different reaction pathways of PCS with the metal precursor have been reported. Thus, titanium, zirconium, or aluminum alkoxides react with PCS upon alkane evolution and formation of Si-O-M units $^{[101,102]}$; whereas metal acetonates were assumed to react upon $\mathrm{Si}-\mathrm{M}$ bond formation and release of acetyl acetone. ${ }^{[101]}$ However, in both cases the chemical interaction between PCS and the metal precursors has not been clarified unambiguously. For instance, the modification of polycarbosilane with metal alkoxides was supported by spectroscopic data (such as FTIR or NMR spectroscopy) only in some cases ${ }^{[102]}$; while in other cases no direct evidence for the formation of the $\mathrm{Si}-\mathrm{O}-\mathrm{M}$ units was obtained and the alkoxide was assumed to be physically incorporated within the PCS-based matrix (i.e., the formation of a blend consisting of alkoxide and PCS) ${ }^{[103]}$ Also, in the case of the reaction of PCS with metal acetylacetonates, no direct evidence of the formation of $\mathrm{Si}-\mathrm{M}$ units was provided (this was claimed only on the basis of the decrease of the amount of $\mathrm{Si}-\mathrm{H}$ bonds in PCS; which is, however, not a strong argument). ${ }^{[101]}$ Recently, a case study on the chemical modification of an allylsubstituted hydrido polycarbosilane with vanadium acetylacetonate indicated that the PCS reacts with metal acetylacetonate complexes upon formation of $\mathrm{Si}-\mathrm{O}-\mathrm{M}$ units, as also reported for the reactions of PCS with metal alkoxides. ${ }^{[104]}$

Thermal treatment of the prepared single-source precursors was shown to lead in a first step to amorphous single-phase ceramics, which subsequently undergo phase separation and crystallization processes to furnish bi- or multi-phase nanocomposites (Figure 5). The conversion of the single-source precursors into ceramics usually consists of two steps: 1) crosslinking processes at low temperatures $\left(100-400{ }^{\circ} \mathrm{C}\right)$ leading to infusible organic/inorganic networks; and 2) ceramization at temperatures up to $1000-1400{ }^{\circ} \mathrm{C}$. Whereas mainly amorphous ceramics are obtained upon pyrolysis, subsequent annealing at high temperatures leads to (poly)crystalline materials. During cross-linking, the single-source precursors are converted into organic/inorganic materials. This process prevents the loss of low molecular weight components of the precursor as well as their fragmentation during ceramization, and thus increases the ceramic yield. Furthermore, the conversion of the single-source precursors into infusible materials prevents their melting during ceramization, while retaining the shape upon pyrolysis. The ceramization process of the cross-linked precursors consists of the thermolysis and evolution of their organic groups at 600$1000{ }^{\circ} \mathrm{C}$. In this temperature range, the conversion of the preceramic materials into amorphous covalent ceramics (usually being single-phasic) occurs. The multifaceted mechanisms involved in the pyrolysis of preceramic polymers are not well understood yet. This is mainly due to the complex structure of the highly cross-linked polymeric materials and the resulting amorphous ceramics. The reactions which occur during pyrolysis can be investigated by solid-state NMR, FTIR, and Raman spectroscopy, as well as via thermogravimetric analysis (TGA) coupled with evolved gas analysis (EGA) (i.e., in situ mass spectrometry and FTIR spectroscopy). ${ }^{[89]}$

Synthesis and phase formation of silicon-based ceramic nanocomposites were studied extensively in the last decade. ${ }^{[87]}$ Pyrolysis of suitable alkoxysilanes, $\mathrm{Si}(\mathrm{OR})_{4}$, or polysiloxanes, 


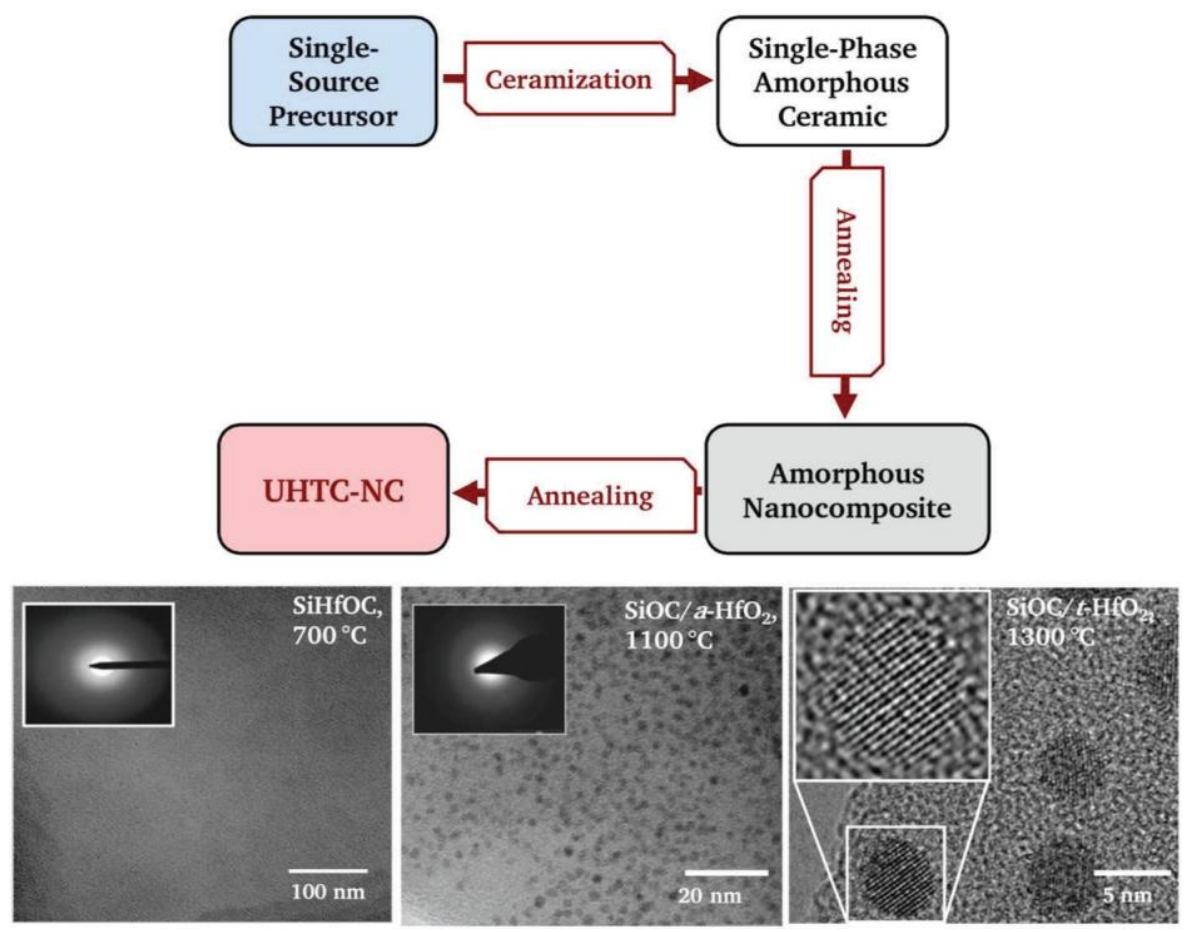

Figure 5. Typical preparative approach of polymer-derived ceramic nanocomposites starting from single-source precursors. ${ }^{[87-89]}$

$\left[\mathrm{Si}(\mathrm{R})_{2}-\mathrm{O}\right] \mathrm{n}$, chemically modified with metal alkoxides was shown to give $\mathrm{MO}_{x} / \mathrm{SiOC}$-based PDC-NCs, as reported for $\mathrm{M}_{4} \mathrm{Al}, \mathrm{Ti}, \mathrm{Zr}$, $\mathrm{Hf}$, etc. For $\mathrm{M} 1 / \mathrm{Zr}$ and $\mathrm{Hf}$ a single-phase SiMOC ceramic is obtained upon pyrolysis at rather low temperatures $\left(\mathrm{ca} .700{ }^{\circ} \mathrm{C}\right)$, while at higher temperatures amorphous $\mathrm{MO}_{2}$ nanoparticles precipitate $\left(800-1100^{\circ} \mathrm{C}\right)$. Upon increasing the annealing temperature to $1300^{\circ} \mathrm{C}, \mathrm{MO}_{2}$ nanoparticles crystallize, forming microstructures comprised of tetragonal zirconia/hafnia particles finely dispersed within an amorphous SiOC matrix. ${ }^{[87,105-107]}$ When using other metals to modify the SiOC ceramic matrix, different and apparently contradictory results have been observed. Thus, in the mentioned case study, the phase composition of different SiMOC systems (M1/\$n, Fe, Mn, V, and Lu) was investigated. ${ }^{[108]}$ Depending on the metal, different ceramic phases formed. For $\mathrm{M} 1 / 4 \mathrm{Mn}$ and $\mathrm{Lu}, \mathrm{MO}_{x} / \mathrm{SiOC}$ ceramic nanocomposites were formed, whereas other compositions revealed the formation of $\mathrm{M} / \mathrm{SiOC}(\mathrm{M} 1 / \mathrm{Sn}), \mathrm{MSi}_{x} / \mathrm{SiOC}\left(\mathrm{M}_{1 / \mathrm{Fe}}\right)$ or $\mathrm{MC}_{x} / \mathrm{SiOC}\left(\mathrm{M}^{1} / 4 \mathrm{~V}\right)$ upon pyrolysis ${ }^{[87,108]}$ (Figure 6). The strong effect of the precursor compositiononthe phaseevolutionuponceramizationreflectsthe reducing conditions during pyrolysis and annealing. Thus, the thermodynamic stability of the metal oxides generated during pyrolysis, particularly with respect to the system $\mathrm{C}-\mathrm{O}$, plays a crucial role. Basedonthermodynamic dataoftherespectiveoxides, the phase composition of SiMOC/SiMCNO ceramics upon annealing at high temperatures can be predicted for different metals (Figure 2). The prediction agrees with the experimental results from this study and those reported in the literature for both SiMOC and SiMCNO ceramic nanocomposites. However, in addition to the stability of the oxides with respect to their reduction in carburizing conditions, some other aspects must be taken into account for predicting the phase composition of SiMOC/SiMCNO nanocomposites, such as thermodynamic stabilization through conversion into silicates (for $\mathrm{MO}_{x}$ being stable with respect to carbothermal conversion into $\mathbf{M}$ ) or into silicides or carbides (for $\mathrm{MO}_{x}$ not being stable against carbothermal reduction).

\section{Synthesis of UHTCs and (Nano)Composites Thereof from Preceramic Polymers}

\subsection{Synthesis of Pure UHTC Phases from Polymeric Precursors}

The synthesis of polymeric precursors used to access UHTC phases can be divided into two distinct categories: 1) methods using chemical modifications of metal alkoxides with, e.g., (poly) alcohols, (poly)acetates or other compounds such as acetylacetone, salicylic acid, etc.; and 2) methods using chemical modification of organometallic compounds such as metallocene-type compounds or other metal complexes with alkyl, alkenyl, alkynyl, or aryl ligands.

Thorne et al. studied the reaction of $\mathrm{Ti}$ isopropoxide with various organic di-acetates leading to polymeric compounds, socalled "polymeric titanates" (Figure 7), which were converted into titanium carbide upon thermal treatment in Ar atmosphere at temperatures of $1000-1600{ }^{\circ} \mathrm{C} .{ }^{[109]}$ All prepared materials contained specific amounts of excess carbon. Interestingly, despite the presence of excess carbon, the obtained $\mathrm{TiC}_{x}$ titanium carbide materials were sub-stoichiometric, with $x$ प4-0.6. ${ }^{[109]}$

Using the same principle, metal alkoxides may be used to prepare polymeric metallates upon reactions with di- 


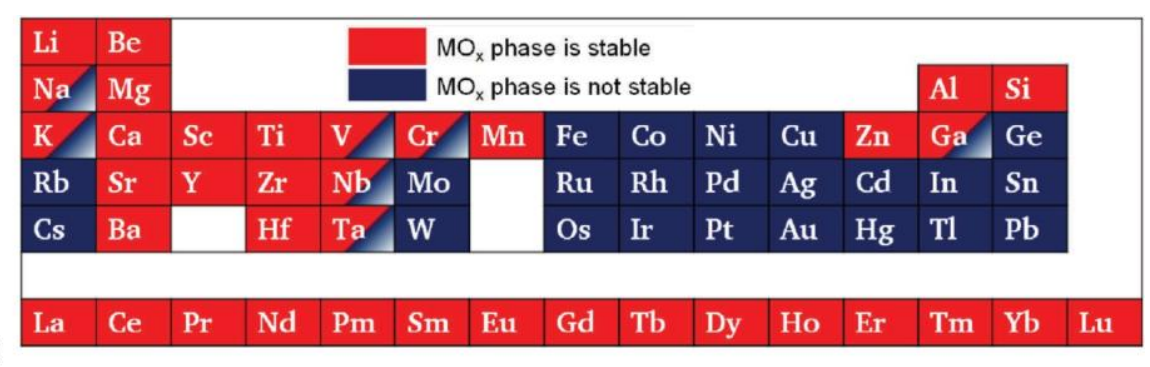

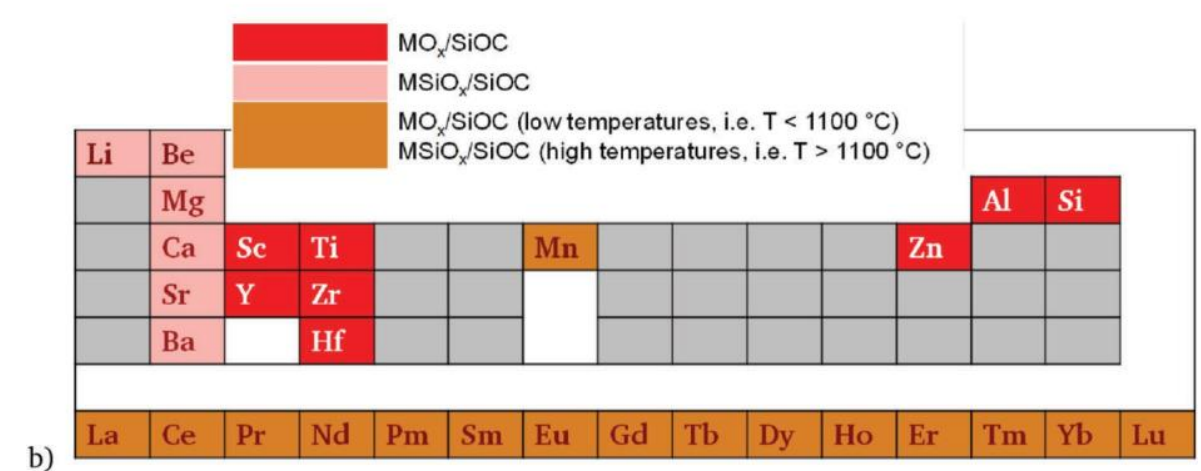

b)

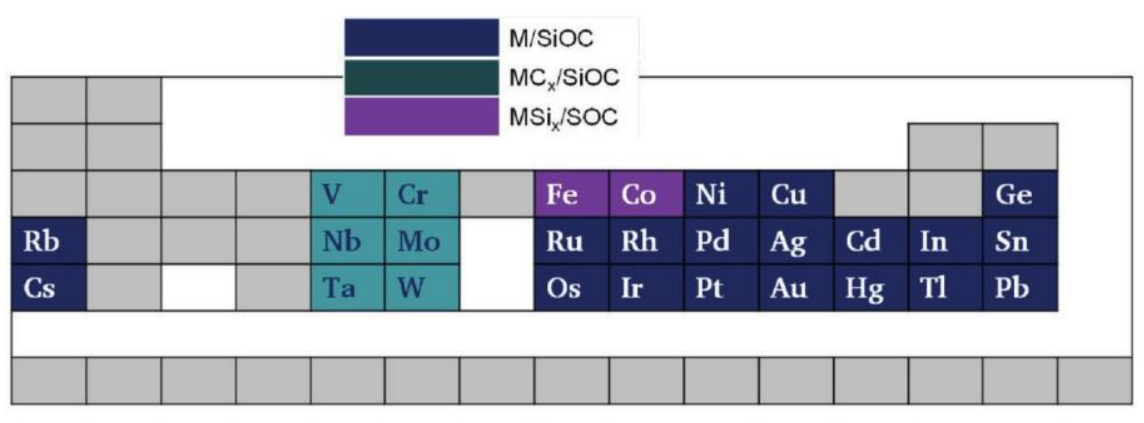

Figure 6. Thermodynamic control in Si-M-O-C-based ceramic nanocomposites: a) oxides of the red marked elements are stable against carbothermal reduction; whereas those of the blue marked elements get reduced in carburizing conditions; b) metals which upon incorporation into SiOC lead directly to silicate formation (pink); the orange marked elements induce firstly the precipitation of $\mathrm{MO}_{x}\left(\right.$ at $T<1100^{\circ} \mathrm{C}$ ), followed by the formation of silicates at higher temperatures; modification of $\mathrm{SiOC}$ with the red marked elements leads to $\mathrm{MO}_{x} / \mathrm{SiOC}$ nanocomposites; $\mathrm{c}$ ) the blue marked metals lead to metallic nanoparticles within the SiOC matrix; the modification of SiOC with the purple marked metals (e.g., Fe, Co) generates metal silicide phases; groups 5 and 6 transition metals (green marked) lead to carbide crystallization within SiOC matrix. ${ }^{[108]}$

alcohols, ${ }^{[110-113]}$ acetylacetone, or combinations thereof ${ }^{[114-120]}$ (Figure 8). Whereas in some cases the prepared polymers were structurally characterized to some extent, many other publications do not consider the molecular structure of the synthesized polymeric metallates and report rather on their conversion into metal carbide compounds upon pyrolysis at elevated temperatures $\left(1000-1600{ }^{\circ} \mathrm{C}\right)$ in inert gas atmosphere.

The conversion of the polymeric metallates into metal carbides is considered to occur via the intermediate formation of metal oxide and excess carbon at temperatures ranging from 800 to $1100-1300{ }^{\circ} \mathrm{C}$; at higher temperatures, the metal oxide phase reacts with carbon and converts into metal carbide. Depending on the molecular structure of the polymeric metallates (i.e., nature and amount of organic substituents), various amounts of excess carbon can be generated in the resulting $\mathrm{C} / \mathrm{MC}_{x}$ nanocomposites.

If the thermal conversion of the polymeric metallates is performed in reactive atmospheres, other compounds are accessible. For instance, Kurokawa et al. converted polymeric metallate precursors in ammonia atmosphere into metal nitrides $\mathrm{MN}_{x}\left(\mathrm{M}\right.$ Thi, Nb, Ta). ${ }^{[122]}$

In a case study, the thermal conversion of a polymeric precursor consisting of polymeric zirconate (polyzirconoxanesal ${ }^{[117]}$ ) modified with boric acid was shown to lead to a mixture of zirconia, boria, and segregated carbon at 1000$1200{ }^{\circ} \mathrm{C}$, which finally converted into phase-pure $\mathrm{ZrB}_{2}$ at temperatures above $1400{ }^{\circ} \mathrm{C}^{[123]}$ (Figure 9).

A second preparative tool to produce UHTC phases from polymeric precursors is based on organometallic precursors. ${ }^{[124-126]}$ Already in the $80 \mathrm{~s}$, titanocene derivatives $\mathrm{CpTiCl}_{3}$, $\mathrm{Cp}_{2} \mathrm{TiCl}_{2}, \mathrm{Cp}_{2} \mathrm{Ti}(\mathrm{R}) \mathrm{Cl}$, and $\mathrm{Cp}_{2} \mathrm{TiR}_{2}$ (Cp cyclo- pentadianyl; $\mathrm{R}$ alkyl, aryl) were/4used to prepare titanium carbide by gas-phase approaches (MO CVD) or thermal decomposition (see ref. [124] and references therein). Moreover, various sandwich compounds of group 4 transition metals $(\mathrm{R}-\mathrm{Cp})_{2} \mathrm{MR}_{2}{ }_{2}(\mathrm{R} 1 / 4 \mathrm{H}$, $\mathrm{CH}_{3}, \mathrm{Si}\left(\mathrm{CH}_{3}\right)_{3} ; \mathrm{R}^{\prime} 1 / 4 \mathrm{Cl}$, alkyl, 


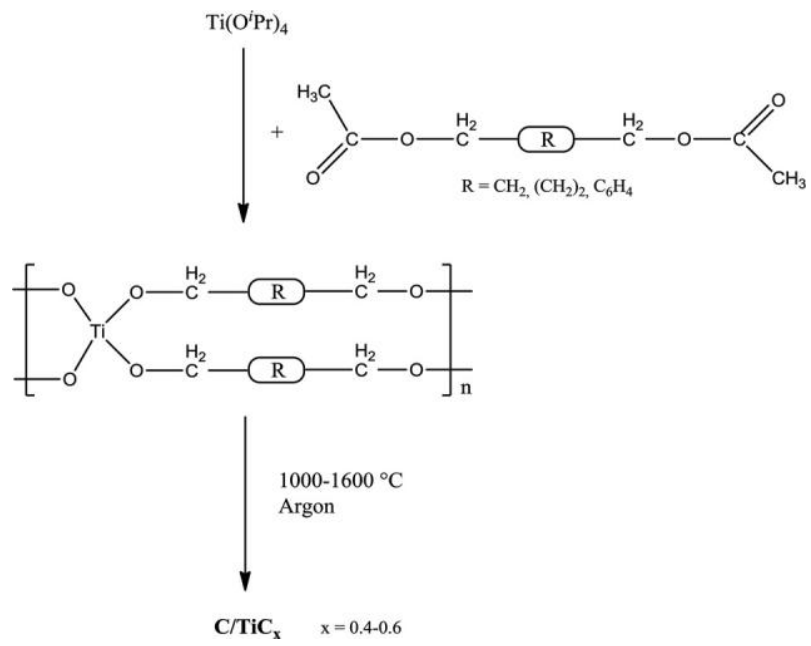

Figure 7. Schematic description of the synthesis of TiC from polymeric titanates. ${ }^{[109]}$

aryl, $\mathrm{NH}_{2}, \mathrm{SH}, \mathrm{OCN}, \mathrm{SCN}$, etc. ${ }^{[124]}$ ) were prepared and converted via thermal treatment in inert gas atmosphere into the respective metal carbides. It was shown that the decomposition of the molecular organometallic compounds occurs via formation of polymeric (macromolecular) intermediates, as shown in Figure 10. ${ }^{[124]}$

Recently, the synthesis of Hf-containing polymeric precursors based on organometallic compounds and their hightemperature conversion into $\mathrm{HfC} / \mathrm{C}$ composites was reported. ${ }^{[125]}$ Typically, $\mathrm{Cp}_{2} \mathrm{HfCl}_{2}$ was reacted with bifunctional dilithio diynes (e.g., 1,4-dilithio-1,3-butadiyne, or 1,4-bis(lithioethynyl)-benzene) to generate the corresponding polymeric precursors. ${ }^{[125]}$ Additionally, a dialkenyl-substituted hafnocene was polymerized upon thermal treatment in the presence of dicumyl peroxide as radical polymerization catalysts (Figure 11). ${ }^{[125]}$

Also, di-vinyl substituted zirconocene was reacted with borane to deliver a polymeric precursor which was thermally converted at $1000-1500{ }^{\circ} \mathrm{C}$ into a $\mathrm{ZrC}_{\mathrm{ZrB}} \mathrm{Zr}_{2}$ nanocomposite. ${ }^{[126]}$

\subsection{Synthesis of (Nano)Composites Consisting of UHTCs and Silica Formers}

The relatively poor oxidation stability of pure UHTCs phases (especially at moderate temperatures, i.e., $500-600^{\circ} \mathrm{C}$ and $1200-$ $1500{ }^{\circ} \mathrm{C}$ ) pushed forward efforts to find different methods to improve their oxidation resistance. Thus, different approaches such as solid solutions, ternary diboride compositions, or the use of secondary phases were studied. Currently the most promising approach involves the use of additive phases (e.g., silicon carbide $^{[127]}$, which can alter the composition and behavior of the oxide scale.

The beneficial effect of $\mathrm{SiC}$ addition on the oxidation behavior of diborides has been explained to rely on the formation of a borosilicate glass layer on the oxidized ceramics. ${ }^{[15]}$ For instance, extensive studies on the oxidation behavior of $\mathrm{SiC}$-containing diboride materials indicate the formation of a silica layer at the beginning of the oxidation

(a)

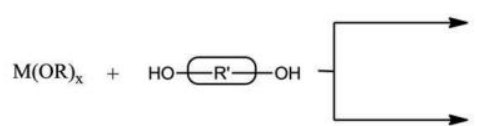

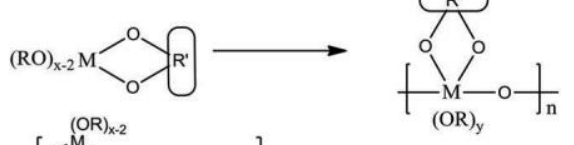
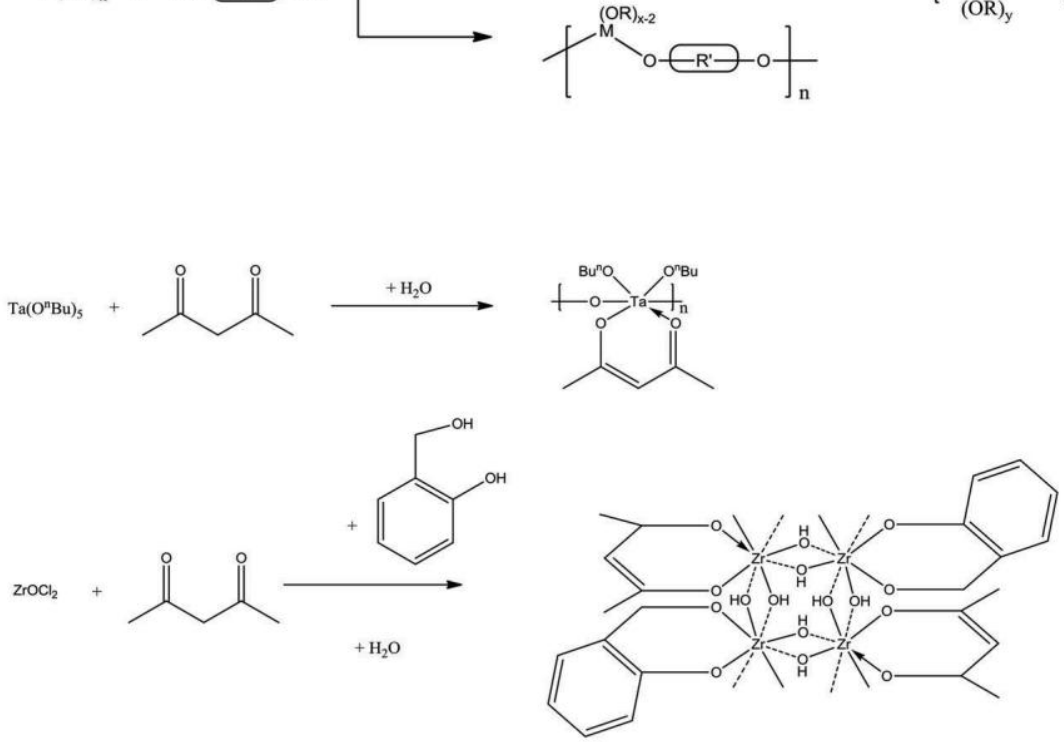

(b)

Figure 8. Synthetic access to polymeric metallates; a) based on metal alkoxides and di-alcohols $1 / \mathrm{R}$ alkyl; $\left.\mathrm{F}_{4}^{0} \mathrm{C}_{x} \mathrm{H}_{2 x}\right)^{[113,121]}$; (b) based on metal alkoxides and acetylacetone ${ }^{[118]}$ as well as on metal salts and a combination of acetylacetone and a di-alcohol. ${ }^{[117]}$ 


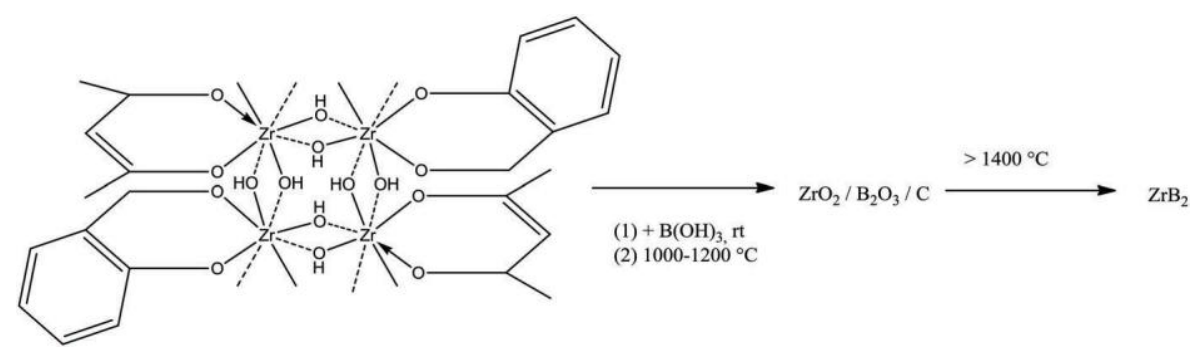

Figure 9. a) Synthesis of $\mathrm{ZrB}_{2}$ upon high thermal conversion of $\mathrm{B}(\mathrm{OH})_{3}$-modified polyzirconoxanesal in argon atmosphere. ${ }^{[123]}$

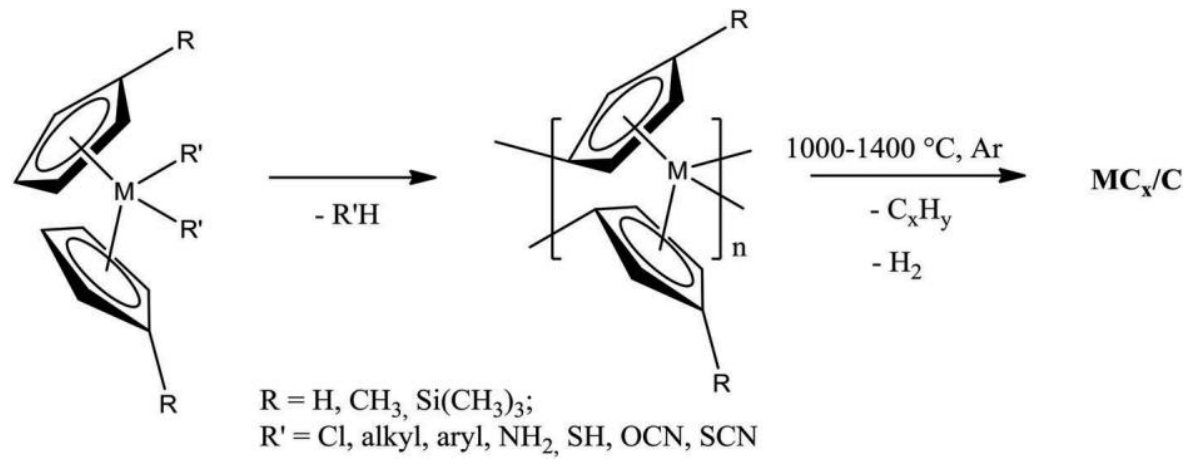

Figure 10. Use of sandwich metal complexes $\left(\mathrm{M}_{1} / 4 \mathrm{Ti}, \mathrm{Zr}, \mathrm{Hf}\right)$ as precursors for the synthesis of $\mathrm{MC}_{x} / \mathrm{C}$ nanocomposites. Their thermal decomposition was shown to occur via formation of polymeric intermediates. ${ }^{[124]}$

a)<smiles>CC=C(C)CCC[C@](O)(CCCCC)OCC</smiles>

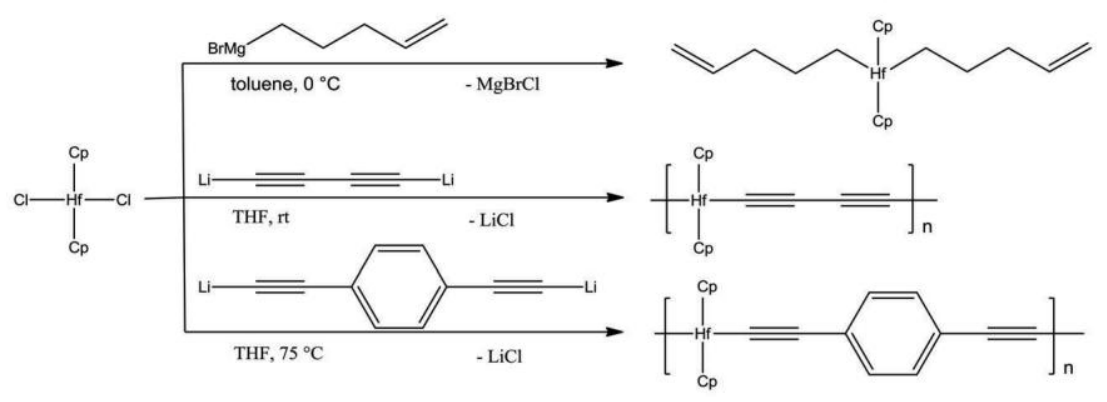

b)

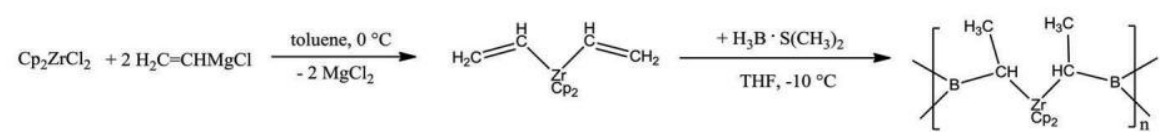

Figure 11. a) Synthesis of non-oxidic preceramic polymers for $\mathrm{HfC}$ starting from $\mathrm{Cp}_{2} \mathrm{HfCl}_{2}{ }^{[125]}$; (b) synthesis of $\mathrm{ZrC} / \mathrm{ZrB}_{2}$ using a preceramic polymer synthesized from a divinyl-substituted zirconocene and borane. ${ }^{[126]}$ 
process. ${ }^{[127]}$ Accordingly, the further oxidation is expected to be limited by the inward oxygen transport through the formed silica scale. Additionally, boria is formed as an oxidation product of the diborides and contributes to a significant decrease of the viscosity of the silica scale. Consequently, the oxygen transport through the borosilicate glassy scale is increased and at the same time boria partially vaporizes from the surface of the glass scale. A multilayer structure has been proposed for the oxidized diborides, which show a porous oxide layer (zirconia, hafnia) below the borosilicate glass layer. At high oxidation temperatures (i.e., beyond $1500{ }^{\circ} \mathrm{C}$ ) an additional layer located between the porous oxide layer and the parent materials was analyzed. It consists of SiC-depleted diboride and was stated to relate to an active oxidation process of silicon carbide. Accordingly, the silicon carbide converts into gaseous silicon monoxide, $\mathrm{SiO}$, which is transported through the porous oxide layer towards the surface, where it reacts with oxygen to form silica, $\mathrm{SiO}_{2} \cdot{ }^{[15,128-130]}$

In addition to silicon carbide as a silica former, silicon nitride ${ }^{[131,132]}$ molybdenum disilicide ${ }^{[133,134]}$ or other transition metal silicides ${ }^{[135,136]}$ have been used. These systems exhibit similar oxidation behavior to that of $\mathrm{MB}_{2} / \mathrm{SiC}$ composites.

\subsubsection{UHTC (Nano) Composites with Low Content of Silica Former (i.e., 10-vol\%)}

Similar to the preparative methods presented in Section 4.1 for UHTC phases, the access to UHTC-based (nano)composites with typically 10-20 vol\% silica former phase (e.g., SiC) was reported in the last decade using the same synthesis tools. Thus, various publications from the last decade report the synthesis of $\mathrm{MC} / \mathrm{SiC}$ (M //4r, Hf, Ta) using polymeric precursors based on polymeric metallates either blended or modified with poly(carbo) silanes. ${ }^{[118,137-139]}$

For instance, a polymeric zirconate (polyzirconoxanesal ${ }^{[117]}$ ) was mixed with boric acid and poly(methylsilylene-ethynylene $)^{[140]}$ and was converted via thermal treatment in argon atmosphere at $1000-1400{ }^{\circ} \mathrm{C}$ into $\mathrm{ZrB}_{2} / \mathrm{ZrC} / \mathrm{SiC} / \mathrm{C}$ composites (Figure 12). ${ }^{[141]}$
Similarly, $\mathrm{ZrC} / \mathrm{SiC}, \mathrm{HfC} / \mathrm{SiC}$ as well as $\mathrm{TaC} / \mathrm{SiC}$ were prepared from corresponding polymeric precursors based on polymeric metallates blended with, e.g., poly(allylhydridocarbosilane). ${ }^{[18,137-139]}$ More recently, a case study reported on the synthesis of $\mathrm{HfC} / \mathrm{SiC}$ from precursors based on polymeric metallates modified with TEOS as a source for $\mathrm{SiC} .^{[142]}$

A different approach was reported by Amorós et al., based on poly(dimethylsilane), PDMS, or poly(methylhydridocarbosilane), PCS, which were mixed with $\mathrm{Cp}_{2} \mathrm{MCl}_{2} \cdot{ }^{[143]}$ The polymeric precursors, resulted from the thermal treatment under reflux condition, were then thermally converted into $\mathrm{MC} / \mathrm{SiC} / \mathrm{C}$ in argon atmosphere at temperatures in the range from 900 to $1400{ }^{\circ} \mathrm{C} .{ }^{[143]}$ This synthesis methods allows adjusting the M:Si ratio (i.e., from $1: 1$ to $1: 10$ ) as well as the amount of free carbon (between ca. 15 and $50 \mathrm{wt} \%$ ) in the prepared nanocomposites. As expected, the use of PCS led to an improved ceramic yield after pyrolysis, which relies on the presence of cross-linking active $\mathrm{Si}-\mathrm{H}$ bonds in PCS. However, for both PDMS and PCS, rather low ceramic yields (10-25 wt \%) after pyrolysis at $900{ }^{\circ} \mathrm{C}$ were reported (Figure 13). ${ }^{[143]}$

\subsubsection{UHTC (Nano)Composites with High Content of Silica Former (i.e., 80-vol\%)}

In this part, we consider (nano)composite materials in which the UHTC phase is preferentially distributed in a silica former matrix such as $\mathrm{Si}_{3} \mathrm{~N}_{4}, \mathrm{SiC}$, and more complex systems like $\mathrm{Si}-\mathrm{B}-$ $\mathrm{C}-\mathrm{N}$. A general strategy is to modify precursors of the silica former phase at molecular scale by metalorganic compounds. This allows the generation of composites or nanocomposites made of (at least) one more phase in addition to the $\mathrm{SiC}, \mathrm{Si}_{3} \mathrm{~N}_{4}$, or Si-C-B-N phase. Such materials often exhibit dramatically enhanced mechanical properties and/or structure stability. ${ }^{[87,144,145]}$ Additional routes consist of 1) mixing polymers with metal fillers, ${ }^{[146]}$ 2) blending two precursors of the desired composition, ${ }^{[147,148]}$ 3) copolymerizing two monomeric precursors to form co-polymers. ${ }^{[149]}$

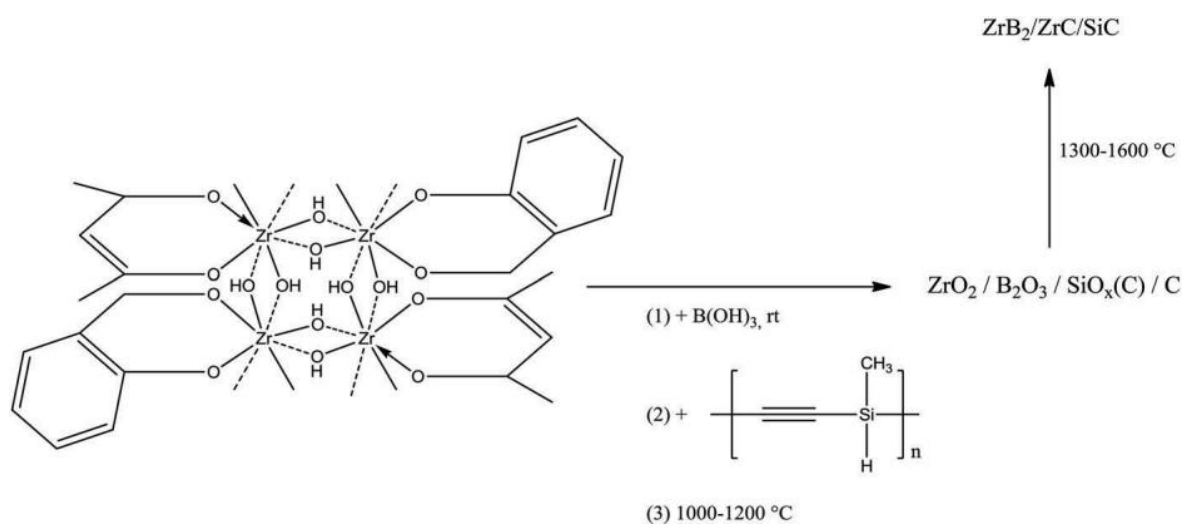

Figure 12. Synthesis of $\mathrm{ZrB}_{2} / \mathrm{ZrC} / \mathrm{SiC}$ from a polymer blend consisting of $\mathrm{B}(\mathrm{OH})_{3}$-modified polyzirconoxanesal and poly (methylsilylene-ethynylene) upon high-temperature thermal treatment in argon atmosphere. ${ }^{[141]}$ 
<smiles>CC(C)(C)[Si](C)(C)C(C)(C)C</smiles><smiles>CC(C)(C)CC(C)(C)[Si](C)(C)C</smiles>

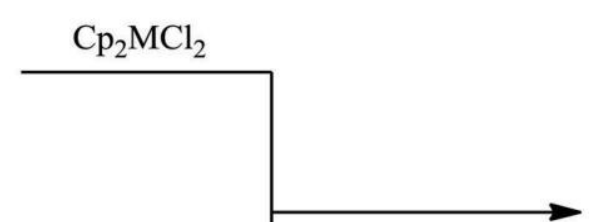

$900-1350{ }^{\circ} \mathrm{C}$

\section{$\mathrm{MC} / \mathrm{SiC} / \mathrm{C}$}

\section{$\mathrm{Cp}_{2} \mathrm{MCl}_{2}$}

Figure 13. Synthesis of $\mathrm{MC} / \mathrm{SiC} / \mathrm{C}$ nanocomposites (M 1/4 Ti, Zr, Hf) from polydimethylsilane or polymethylhydridocarbosilane modified with metallocene dichlorides (Cp 1/4 cyclopentadienyl). ${ }^{[143]}$

(Nano)Composites with $\mathrm{Si}_{3} \mathrm{~N}_{4}(\mathrm{C}, \mathrm{O})$ Matrix as Silica Former: Riedel et al. described the reaction between $\mathrm{TiCl}_{4}$ and bis(trimethylsilyl)carbodiimide leading to a single source polymeric $\left\{\left[\mathrm{Ti}(\mathrm{NCN})_{213} \mathrm{NCNSiMe}_{3}\right\}\right.$ compound as precursor suitable to form a $\mathrm{TiC}_{0.3} \mathrm{~N}_{0.7} / \mathrm{Si}-\mathrm{C}-\mathrm{N}$ nanocomposite. ${ }^{[150]}$ Accordingly, the main process to design UHTC nanocomposites with $\mathrm{Si}_{3} \mathrm{~N}_{4}$ and $\mathrm{Si}-\mathrm{N}(\mathrm{C}, \mathrm{O})$ matrices as silica former is based on the chemical modification of pre-formed preceramic polymers with low molecular weight species such as metalorganic compounds to form so called polymeric single-source precursors (SSP), in which a uniform chemical composition is established at the molecular scale. Then, the SSPs are converted in a first pyrolysis step under ammonia to reduce or even eliminate the carbon-based organic groups present in the polymer while a single-phase amorphous ceramic is generated at $1000{ }^{\circ} \mathrm{C}$. The latter is subsequently heat-treated at higher temperatures under nitrogen to form the UHTC nanophase providing nanocomposites composed of $\mathrm{MN}$ nanocrystals ( $\mathrm{M} 1 / 4 \mathrm{Ti}, \mathrm{Hf})$ homogeneously distributed in an amorphous matrix. ${ }^{[151-155]}$ The first report focused on the design of $\mathrm{TiN} / \mathrm{Si}_{3} \mathrm{~N}_{4}$ nanocomposites involved the reaction between a commercially available polysilazane, i.e., perhydropolysilazane (PHPS), and a metallorganic compound namely tetrakisdimethylaminotitanium (TDMATi) in a 2.5:1 molar ratio. The reaction formed a perhydropolytitanosilazane with a chemical formula of $\left[\mathrm{Si}_{1.1} \mathrm{Ti}_{0.4} \mathrm{C}_{2.2} \mathrm{~N}_{1.1} \mathrm{H}_{6.2}\right]_{n}$ and a molecular weight of $4200 \mathrm{~g} \mathrm{~mol}^{-}$ ${ }^{1}{ }^{[152]}$ After ammonolysis at $40{ }^{\circ} \mathrm{C}$, the polymer could be warm-pressed at $110{ }^{\circ} \mathrm{C}$ under $162 \mathrm{MPa}$ uniaxial pressure. Subsequent pyrolysis of the formed body under ammonia $\left(1000^{\circ} \mathrm{C}\right)$ and nitrogen $\left(1300^{\circ} \mathrm{C}\right)$ produced bulk nanocomposites with $70 \mathrm{wt} \%$ yield and comprised of TiN nanocrystallites with an average diameter of $3.1 \mathrm{~nm}$ homogeneously embedded in an amorphous $\mathrm{Si}_{3} \mathrm{~N}_{4}$ matrix. The in situ controlled growth of TiN nanocrystals associated with the absence of $\mathrm{Si}_{3} \mathrm{~N}_{4}$ grain growth and the purity of the materials provided Vickers hardness as high as $25.1 \mathrm{GPa}$. Later, the same authors investigated the chemistry behind the process of preparing such nanocomposites to gain new insight into the reaction mechanisms of these materials and to understand the role of chemistry behind the processability and design of TiN/Si ${ }_{3} \mathrm{~N}_{4}$ nanocomposites. ${ }^{[154]}$ Based on complementary characterization tools including solid state NMR, elemental analyses and infrared spectroscopy, two mechanisms have been proposed to govern the reaction between polysilazane and TDMATi. Mechanisms involve $\mathrm{N}-\mathrm{H}$ and $\mathrm{Si}-\mathrm{H}$ bonds present in polysilazanes as well as $\mathrm{N}\left(\mathrm{CH}_{3}\right)_{2}$ groups in TDMATi (Figure 14).

Detailed solid-state NMR studies in combination with quantitative thermogravimetry provided a comprehensive understanding of the polytitanosilazane-to-nanocomposite transformation process. Accordingly, a predominantly amorphous ceramic network is formed first at $1000^{\circ} \mathrm{C}$ under ammonia. Subsequent annealing in $\mathrm{N}_{2}$ at $1400^{\circ} \mathrm{C}$ produces nanocomposites comprised of homogeneously dispersed TiN nanocrystals embedded in an amorphous matrix $\left(\mathrm{Si}_{3} \mathrm{~N}_{4}\right)$. The structural evolution above $1000{ }^{\circ} \mathrm{C}$ is closely related to 1) the chemistry of polysilazanes (precursors of the $\mathrm{Si}_{3} \mathrm{~N}_{4}$ matrix), 2) the molar $\mathrm{Si}$ :Ti ratio fixed during the synthesis of the polytitanosilazane, and 3 ) the material shape (powder, mesoporous monoliths, or dense materials). ${ }^{[153]}$ It appears that $\mathrm{TiN}$ is the first phase to nucleate at $1400{ }^{\circ} \mathrm{C}$ in such materials and the TiN crystallite growth mainly depends on the molar Si:Ti ratio fixed in the polytitanosilazane. Interestingly, the onset of the $\mathrm{Si}_{3} \mathrm{~N}_{4}$ crystallization temperature in $\mathrm{MN} / \mathrm{Si}_{3} \mathrm{~N}_{4}$ nanocomposites is shifted upward with increase of

the volume fraction of $\mathrm{TiN}$ in the ceramics. The $\mathrm{Si}_{3} \mathrm{~N}_{4}$ crystallization was significantly reduced even after annealing at $1800{ }^{\circ} \mathrm{C}$ for the nanocomposite with the highest Ti content. Similar effects have also been observed by replacing titanium by hafnium to form $\mathrm{HfN} / \mathrm{Si}_{3} \mathrm{~N}_{4}$ nanocomposites from $\mathrm{Hf}$-modified

PHPS. In the latter, HfN nanocrystals are embedded in an amorphous $\operatorname{SiN}_{x}$ matrix after annealing at $1300{ }^{\circ} \mathrm{C}$ whereas full crystallization of both phases is found after annealing at $1600{ }^{\circ} \mathrm{C} .{ }^{[155]}$ Thus, it appears that the crystallization behavior of the $\mathrm{Si}_{3} \mathrm{~N}_{4}$ matrix in $\mathrm{MN} / \mathrm{Si}_{3} \mathrm{~N}_{4}$ nanocomposites is governed by the chemistry of the polysilazanes and the $\mathrm{Si}: \mathrm{M}$ ratio fixed at the polysilazane level.

By changing the chemistry of the precursors and using polyhydridomethylsiloxane (PHMS) as a matrix precursor and titanium tetra-n-butoxide as a precursor of the nanophase, nanocomposites made of TiN nanocrystals of approximately $=4 \mathrm{~nm}$ size homogeneously distributed in an amorphous SiOCN matrix have been generated at $1200{ }^{\circ} \mathrm{C} .{ }^{[151]}$ The photocatalytic properties of the nanocomposites with respect to dye degradation have been evaluated. The visible light photocatalytic activity 
<smiles>[R][Si](C)(NC)N[Si]([R])(C)NC</smiles><smiles>[R][Si](C)(C)N([C@H](C)NC)[Si]([R])(C)NC</smiles><smiles>CN[Si](C)(C)N[SiH](C)N[Si](C)(NC)N(C)C(C)C</smiles>

Figure 14. Reaction between $\mathrm{NH}$ and $\mathrm{SiH}$ units present in polysilazanes and $\mathrm{NCH}_{3}$ groups present in TDMATi. ${ }^{[154]}$

of the synthesized nanocomposite resulted in a degradation efficiency of $64 \%$ and the hydroxyl radicals were found to be the active species.

(Nano)Composites with $\mathrm{SiC}(\mathrm{N})$ Matrix as Silica Former - MC/ $\mathrm{SiC}(N)$ and $M N / S i C(N)$ (Nano)Composites: The design of (nano) composites with $\operatorname{SiC}(\mathrm{N})$ matrix as silica former has been well reported in the literature. The first strategy consists of using passive or active fillers mixed in the $\mathrm{SiC}(\mathrm{N})$ precursor. Whereas passive fillers such as $\mathrm{ZrC}$ powders do not interact with the $\mathrm{SiC}$ precursor upon pyrolysis in order to form additional phases in the $\mathrm{SiC}(\mathrm{N})$ material after the pyrolysis and annealing treatments, ${ }^{[156,157]}$ active fillers do interact with preceramic polymers. As an illustration, Seyferth et al. investigated this approach to prepare $\mathrm{Si}-\mathrm{C}-\mathrm{W}$ systems using polysilazanes and $\mathrm{W}$ powders. ${ }^{158]} \mathrm{In}$ the same study, Ti and $\mathrm{Zr}$ were combined with polysilazane and pyrolyzed under $\mathrm{Ar}$ at $1500{ }^{\circ} \mathrm{C}$ to form mixtures of TiN, $\mathrm{ZrN}$, and $\mathrm{SiC}$. This approach offers easy access to composite materials in a relatively large range of compositions according to the choice of both the metal and the organosilicon precursor. As an illustration, the pyrolysis of polycarbosilane (PCS) mixed with $\mathrm{Ti}, \mathrm{Zr}$, and $\mathrm{Hf}$ to $1500^{\circ} \mathrm{C}$ in a stream of argon delivered $\mathrm{MC} / \mathrm{SiC}$ composites. ${ }^{[159]}$ Using a carbon-rich $\mathrm{SiC}$ precursor, i.e., $\left[\mathrm{Me}_{2} \mathrm{SiC} \div \mathrm{C}\right]_{\mathrm{n}}$, as a reagent and $\mathrm{Ti}, \mathrm{Zr}$, and $\mathrm{Hf}$ as active fillers, different $\mathrm{MC} / \mathrm{SiC}$ compositions have been prepared ${ }^{[159]}$ In contrast, the pyrolysis of a Si-rich $\mathrm{SiC}$ precursor, i.e., $\left[(\mathrm{MeSiH})_{\sim 0.4}(\mathrm{MeSi})_{\sim 0.6}\right]_{\mathrm{n}}$, under $\operatorname{argon}$ at $1500{ }^{\circ} \mathrm{C}$ led to $\mathrm{TiC}$ and $\mathrm{Ti}_{5} \mathrm{Si}_{3}$ phases. Riedel et al. mixed titanium powders with polysiloxane to form after pyrolysis to $1100{ }^{\circ} \mathrm{C}$ mixtures of titanium carbide and metal silicide. ${ }^{[160]}$ More recently, a series of studies has been reported on the dispersion of titanium powders in polycarbosilanes with the objective to form the well-known MAX phase $\mathrm{Ti}_{3} \mathrm{SiC}_{2} \cdot{ }^{[161-164]}$ All these works illustrate the simplicity of this polymer approach. However, the use of nanoparticles (diameter $\$ 0 \mathrm{~nm}$ ) as active nanofillers in organosilicon polymers was not reported despite nanostructured materials can provide improved or new properties compared to their microstructured counterparts. In this context, the use of allylhydridopolycarbosilane (AHPCS) as a reagent and titanium (Ti) nanopowders as active fillers (Figure 15) has been described to generate $\mathrm{TiC} / \mathrm{SiC}$ nanocomposites. ${ }^{[165]}$

During the pyrolysis under argon, Ti nanopowders reacted with carbon-based gaseous by-products (methane, ethylene, etc.) that evolved from AHPCS during its decomposition and/or with carbon radicals to form $\mathrm{TiC}$ as a unique phase after pyrolysis to $800^{\circ} \mathrm{C}$. The dominating crystalline $\mathrm{TiC}$ phase further crystallized in the temperature range $800-1000^{\circ} \mathrm{C}$ while marking the $\mathrm{Ti}_{3} \mathrm{SiC}_{2}$
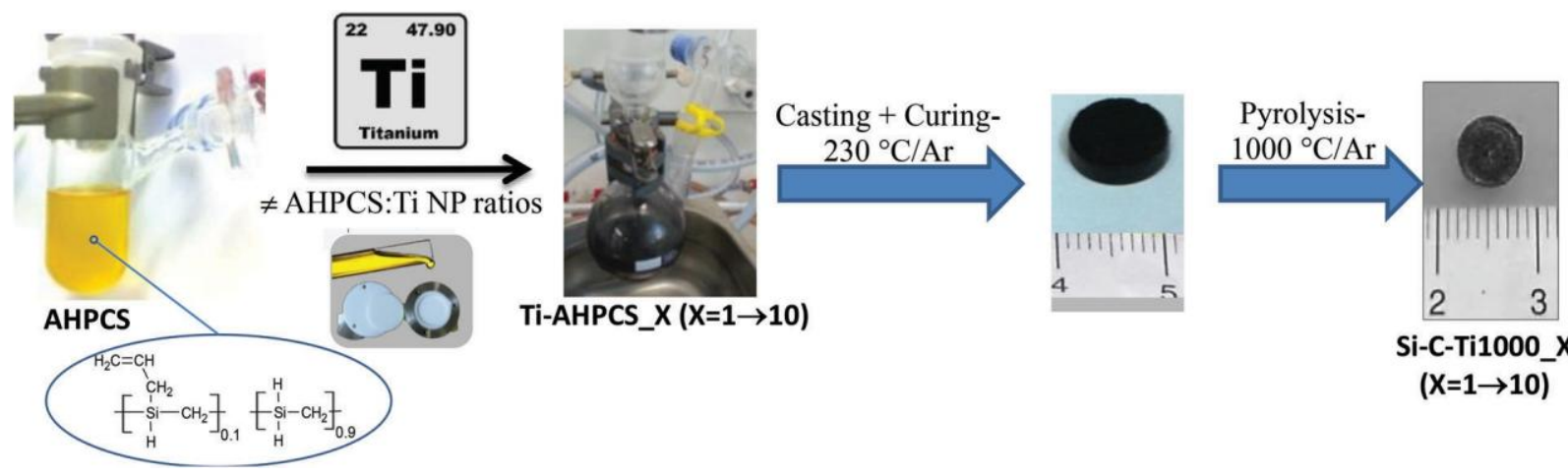

Si-C-Ti1000_X

$(X=1 \rightarrow 10)$

Figure 15. Overall process for preparing dense monolithic Si-C-Ti components. ${ }^{[165]}$ 
and $\mathrm{Ti}_{5} \mathrm{Si}_{3}$ nucleation. ${ }^{[165]}$ This procedure suggests that $\mathrm{Ti}$ and/or TiC reacted with the AHPCS-derived matrix to form the $\mathrm{Ti}_{5} \mathrm{Si}_{3}$ and $\mathrm{Ti}_{3} \mathrm{SiC}_{2}$ phases. Upon further pyrolysis above $1000{ }^{\circ} \mathrm{C}$, monolithic $\mathrm{TiC} / \mathrm{SiC}$ composites gradually formed at $1400{ }^{\circ} \mathrm{C}$. Most probably, free carbon identified in the samples played a key role in the formation of $\mathrm{TiC}$ and $\mathrm{SiC}$ from $\mathrm{Ti}_{3} \mathrm{SiC}_{2}$ and $\mathrm{Ti}_{5} \mathrm{Si}_{3}$ phases. Based on these studies, it appears that $\mathrm{SiC}$ precursors represent appropriate reagents to successfully generate $\mathrm{MC} / \mathrm{SiC}$ composites via their mixture with metal $(\mathrm{M})$ powders. However, the major disadvantage of this approach is that the processing may result in aggregation of the powders leading to compounds with an inhomogeneous distribution of the phases. Therefore, solution-based methods, in which the $\mathrm{SiC}$ and $\mathrm{MC}(\mathrm{M} / 4 \mathrm{Ti}, \mathrm{Zr}$, Hf) precursors are mixed on the molecular scale, as well as single-source precursors (SSP) are preferred although more expensive.

The modification of $\mathrm{SiC}$ with $\mathrm{Ti}, \mathrm{Zr}$, and $\mathrm{Hf}$ has been proposed since the 80 s to design (nano)composites with a $\mathrm{SiC}$ matrix as a silica former. ${ }^{[12,101-103,166-176]}$ Since that time, different synthetic strategies are described in the literature to form $\mathrm{MC} / \mathrm{SiC}(\mathrm{N})$ (nano)composites, by using either mixed precursors (or blended polymers), or by inserting the metal in the polymer at the level of the macromolecule (i.e., chemical modification) or directly in the monomer (single-source precursors).
Mixing of two polymers respectively with $\mathrm{M}$ and $\mathrm{Si}$ in their structures represent an easy access to $\mathrm{MC} / \mathrm{SiC}$ composites. ${ }^{[177]}$ Following this route, a polycarbosilane and a polyzirconobutanediol were blended in toluene to be pyrolyzed at $1500{ }^{\circ} \mathrm{C}$ under argon. ${ }^{[178]}$ The distribution of the $\mathrm{ZrC}$ phase as well as the size of the $\mathrm{ZrC}$ crystals correlated with the time of the drying method.

Another route to access $\mathrm{MC} / \mathrm{SiC}$ composites was based on the addition of a crosslinking agent, namely divinylbenzene (DVB), to the blended polymers consisting of polyhafnoxanesal ([-Hf-O-

Hf- $]_{n}$ ), and PCS. ${ }^{[139]} \mathrm{HfC}$ was generated at high temperature through a carbothermal reduction of the $\mathrm{Hf}-\mathrm{O}-\mathrm{C}$ phase by the excess carbon in-situ formed from DVB and PCS during

pyrolysis. After annealing at $1600{ }^{\circ} \mathrm{C}$ under argon, HfC/SiC powder with diameter less than $100 \mathrm{~nm}$ and a composition of ca. $13.5 \mathrm{vol} \% \mathrm{HfC}, 64.5 \mathrm{vol} \% \mathrm{SiC}$, and $22 \mathrm{vol} \%$ excess carbon was formed (Figure 16).

A blend composed of a polyzirconoxanesal ( $\mathrm{Zr}$ source), a phenyl-terminated polysilane ( $\mathrm{Si}$ source), and bisphenol-A type benzoxazine was reacted to lead to a multi-element precursor, with ring-opening, condensation, and addition polymerizations. ${ }^{[179]}$ This method was used to fabricate $\mathrm{ZrC} /$ $\mathrm{SiC}$ ceramics, after a suitable pyrolysis of the complex polymeric network up to $1600{ }^{\circ} \mathrm{C}$, under nitrogen atmosphere. The ceramic yields ranged from 40 to $65 \%$, and the

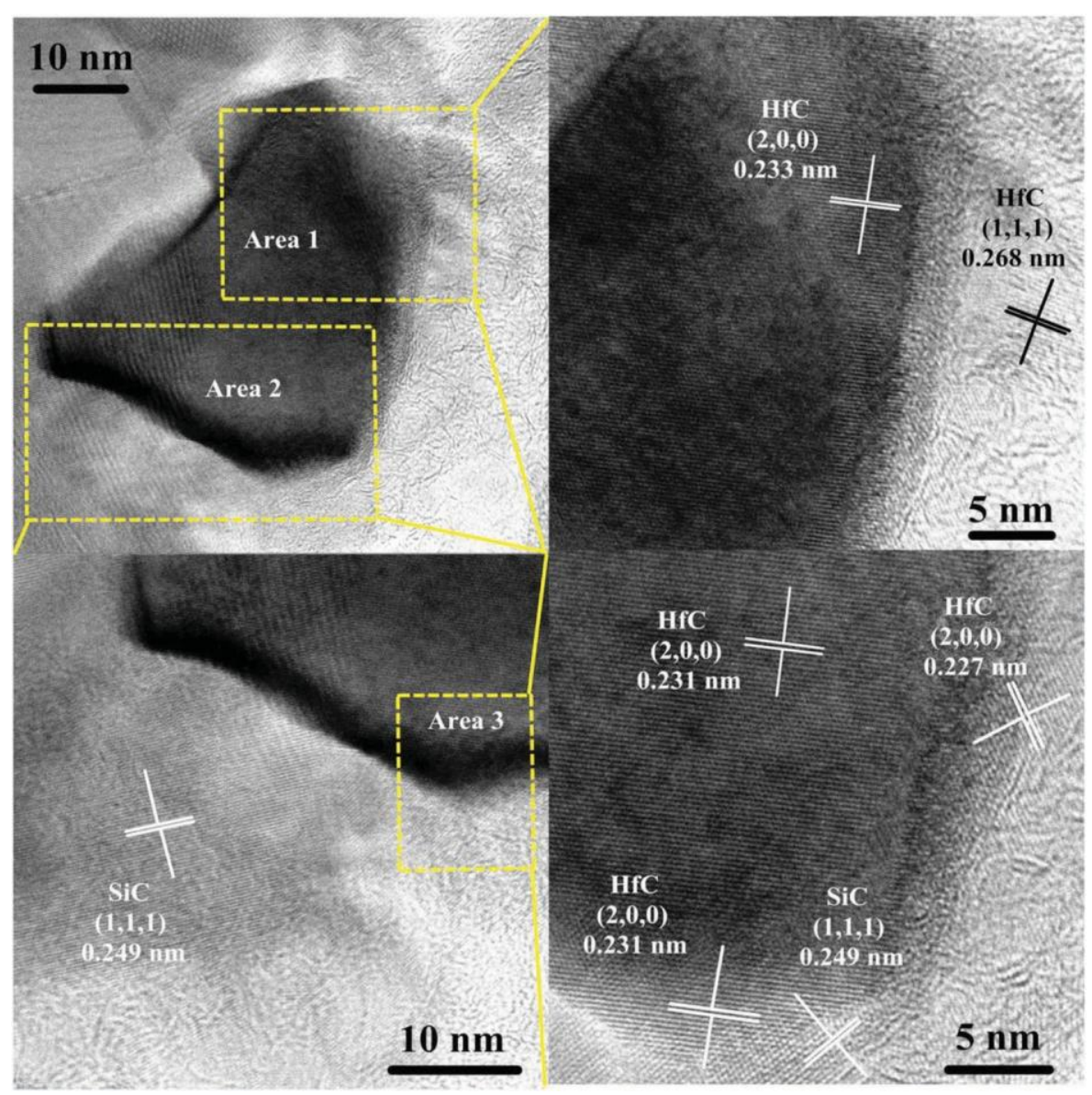

Figure 16. TEM images of polymer-derived $\mathrm{HfC} / \mathrm{SiC}$ powders at $1600{ }^{\circ} \mathrm{C}^{[139]}$ (reprinted with permission from Wiley, 2018). 
microstructures revealed well-distributed $\mathrm{Zr}, \mathrm{Si}$, and $\mathrm{C}$ elements in the final material.

The chemical modification of a selected polysilane or a polycarbosilane containing reactive groups like $\mathrm{SiH}$ sites with a metal-containing precursor is probably the most common approach which has been explored to prepare $\mathrm{MC} / \mathrm{SiC}$ composites and nanocomposites. Starting from polymethylsilane, Wang et al. prepared a series of polyzirconomethylsilanes namely PZMS by adjusting the weight ratio between the $\mathrm{Zr}$ based compound, i.e., $\mathrm{Cp}_{2} \mathrm{Zr}\left(\mathrm{CH}^{1} / \mathrm{CH}_{2}\right)_{2}$ and the polymethylsilane. ${ }^{[180]}$ The pyrolysis of PZMS resulted in a ceramic yield of $78.4 \mathrm{wt} \%$. Crystalline $\mathrm{ZrC}$ and $\mathrm{SiC}$ phases were well distributed in the composite prepared at $1600{ }^{\circ} \mathrm{C}$ with the content of $\mathrm{ZrC}$ as high as $54.6 \%$ by weight. It was shown that the introduction of $\mathrm{ZrC}$ prevented the fast growth of crystalline $\beta$-SiC. Based on their work focused on the design of $\mathrm{ZrC} / \mathrm{SiC}$ composites ${ }^{[174]}$ and on the pioneering report of Latorre et al., ${ }^{[143]} \mathrm{Yu}$ et al. reported the preparation of $\mathrm{TiC} / \mathrm{SiC}$ composites through the reaction of AHPCS and dichlorobis(cyclopentadienyl)titanium $\left(\mathrm{Cp}_{2} \mathrm{TiCl}_{2}\right) .{ }^{[181]}$ The reaction was performed with three $\mathrm{Cp}_{2} \mathrm{TiCl}_{2}$ :AHPCS ratios, i.e., 1:3, 1:2, and 1:1, followed by a pyrolysis in an argon atmosphere up to $900{ }^{\circ} \mathrm{C}$ and subsequent annealing at $1600{ }^{\circ} \mathrm{C}$ in an argon flow. It was shown that $\mathrm{Cp}_{2} \mathrm{TiCl}_{2}$ played a double role: 1) The cross-linking of the hybrid precursors was significantly catalyzed by $\mathrm{Cp}_{2} \mathrm{TiCl}_{2}$ and $\mathrm{Si}-\mathrm{Si}$ dehydrocoupling and hydrosilylation effectively occurred during mixing. 2) $\mathrm{Cp}_{2} \mathrm{TiCl}_{2}$ reacted with AHPCS through reaction of $\mathrm{SiH}$ and $\mathrm{TiCl}$ groups forming $\mathrm{HCl}$. These two functions of $\mathrm{Cp}_{2} \mathrm{TiCl}_{2}$ significantly improved the ceramic yield of the polymer (80.8 wt $\%$ ) compared to prisitine AHPCS (60.5 wt\%). The chemical composition as well as the microstructure could be tailored by the $\mathrm{Cp}_{2} \mathrm{TiCl}_{2}$ :AHPCS ratios. AHPCS was also used to react with borazine via hydroboration before adding titanium butoxide $\mathrm{Ti}(\mathrm{OBu})_{4}$ to be cross-linked at $170{ }^{\circ} \mathrm{C} .{ }^{[182]}$ By fixing $\mathrm{B}$ and excess $\mathrm{C}$, Ti allowed to form crystalline $\mathrm{TiB}_{2}$ and $\mathrm{TiC}$ phases in addition to the crystalline $\mathrm{SiC}$ phase through pyrolysis at $900{ }^{\circ} \mathrm{C}$ and annealing at $1800{ }^{\circ} \mathrm{C}$ under argon. Polycarbosilanes may also react with alkene functional groups present in metal- containing molecules through hydrosilylation. This approach was developed by Wang et al. using $\mathrm{Zr}$ containing mole- cules. ${ }^{[183,184]}$ The authors performed functionalization of zirconocene dichloride $\left(\left(\mathrm{Cp}_{2} \mathrm{ZrCl}_{2}\right)\right.$ by using an organomagnesium reagent (i.e., allyl- $\left(\mathrm{CH}_{4} \mathrm{CHCH}_{2} \mathrm{MgCl}\right)$ or vinyl-magnesium chloride $\left.{ }^{1}\left(\mathrm{CH}_{2} \mathrm{CHMgCl}\right)\right)$. Then, the as-obtained diallylbis(cyclopentadienyl)zirconium (DACZ) depicted in Figure 17 could react with a low molecular weight polycarbosilane to give a soluble crosslinked preceramic polymer labelled PCS-DACZ via free radical polymerization. ${ }^{[184]}$ The PCS-DACZ displayed a relatively high ceramic yield of $80 \mathrm{wt} \% \mathrm{ZrC} / \mathrm{SiC} / \mathrm{C}$ nanocomposites were retrieved after a pyrolysis at $1400^{\circ} \mathrm{C}$ under argon atmosphere, displaying an excellent high-temperature resistance up to $2000{ }^{\circ} \mathrm{C}$ with well-dispersed $\mathrm{ZrC}$ nanoparticles.

This strategy was also investigated with a zirconocene dichloride functionalized with vinyl groups to generate $\mathrm{ZrC} /$ $\mathrm{SiC}$ ceramics with a high $\mathrm{Zr}$ content. ${ }^{[184]}$ The ceramics showed a good resistance to oxidation in air up to $1400{ }^{\circ} \mathrm{C}$. In parallel to the reactivity of alkene groups, other methods were attempted involving $\mathrm{N}$ - or O-containing complexes of zirconium. For example, the two-step reaction between allylamine $\left(\mathrm{C}_{3} \mathrm{H}_{7} \mathrm{~N}\right)$, zirconium tetrachloride $\left(\mathrm{ZrCl}_{4}\right)$, polymethylsilane (PMS), and $14 \mathrm{H}_{2} \mathrm{CHCH}_{2} \mathrm{MgCl}$ led to a soluble $\mathrm{ZrC} / \mathrm{SiC}$ precursor. The composite was isolated in a $49 \%$ yield at $1000{ }^{\circ} \mathrm{C}$, and the material exhibited less than $2 \mathrm{wt} \%$ of $\mathrm{N}$ in its structure. ${ }^{[185]}$ In the field of polymer-derived ceramics, oxygen containing-zirconium complexes are often used. Reacting with polycarbosilanes, they can lead to $\mathrm{ZrC} / \mathrm{SiC}$ ceramics after a suitable heat-treatment. In this way, Devasia et al. modified polycarbosilanes with zirconium acetylacetonate $\left(\mathrm{Zr}(\mathrm{Acac})_{4}\right)$ to synthesize polyzirconocarbosi-

lanes. ${ }^{[186]}$ The authors introduced different $\mathrm{Zr}$ :Si ratio and showed that the ceramic yield of the precursors was improved by the introduction of $\mathrm{Zr}$, to reach $76 \mathrm{wt} \%$ at $1200{ }^{\circ} \mathrm{C}$, under argon.

HRTEM analyses were undertaken on the composites heattreated at $1650{ }^{\circ} \mathrm{C}$, revealing the presence of an oxide-free $\mathrm{ZrC} /$ $\mathrm{SiC}$ composite.

In the case of hafnium, an earlier work reported on the synthesis of a precursor suitable to form $\mathrm{HfC}_{x} \mathrm{~N}_{1-x} / \mathrm{SiC}$ nanocomposites. ${ }^{[187]}$ The procedure involved the reaction between AHPCS, and tetrakis(dimethylamido)hafnium ( $\mathrm{Hf}(\mathrm{N}$ $\left.\left(\mathrm{CH}_{3}\right)_{2}\right)_{4}$, TDMAH) according to Figure 18.

The functionalization of AHPCS was confirmed by IR and NMR spectroscopy. Amorphous SiHfCN-based ceramic powders were then densified using spark plasma sintering (SPS) at
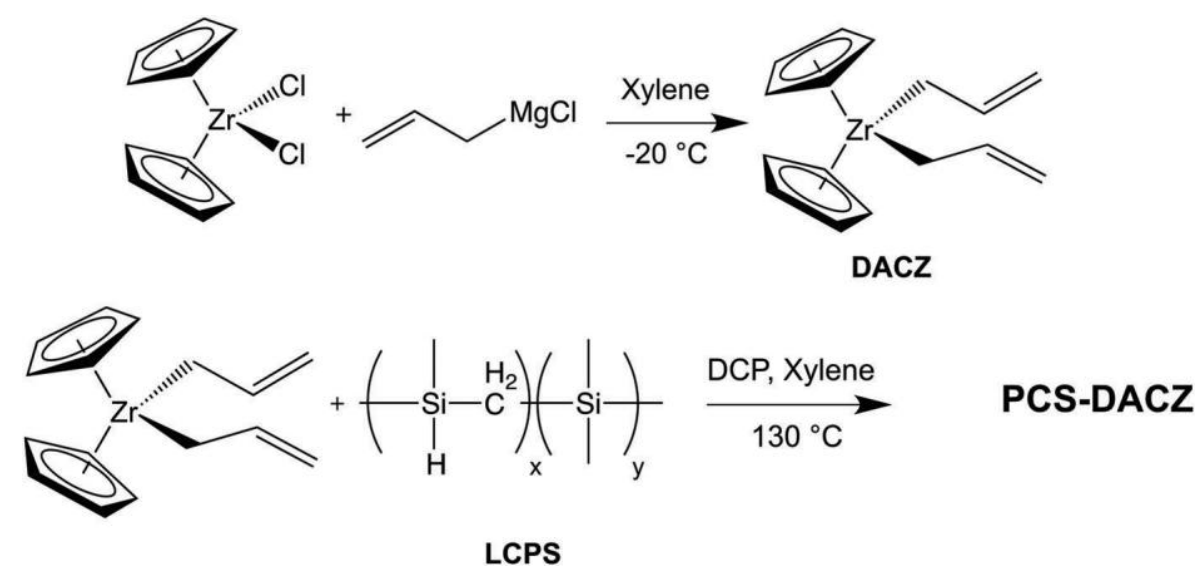

Figure 17. Synthesis of DACZ and reaction with a low molecular weight PCS. ${ }^{[183]}$ 


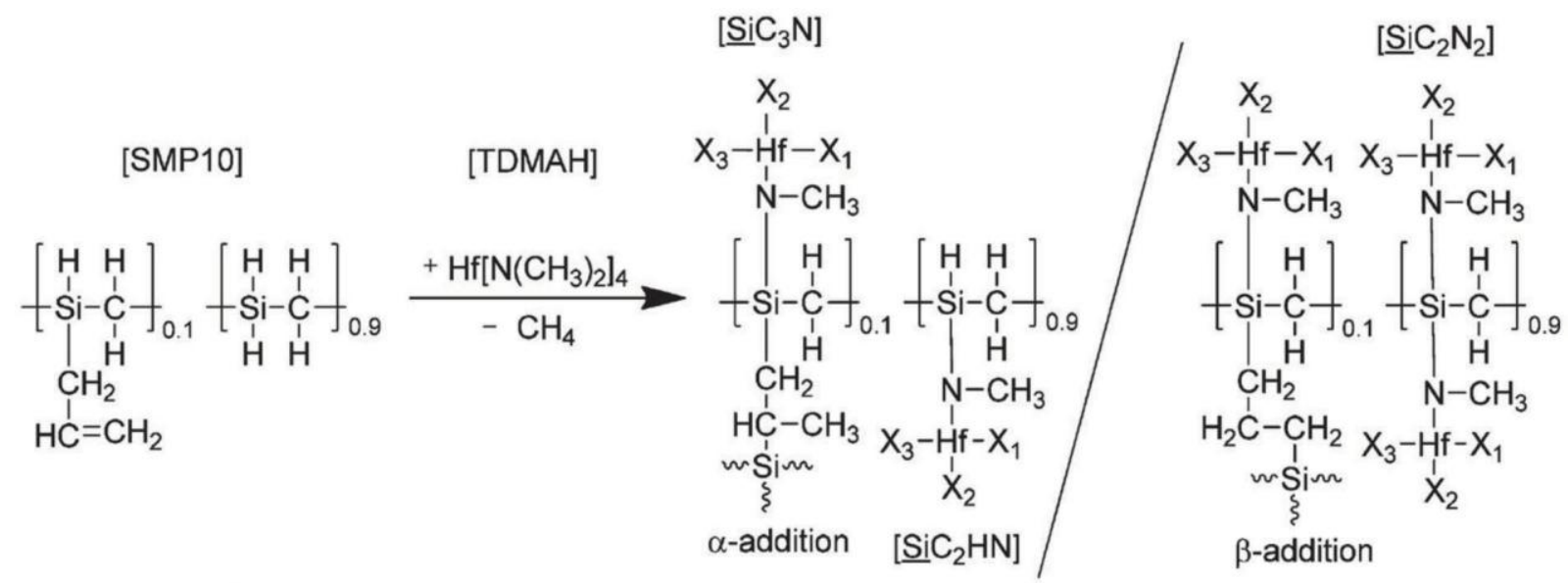

$\mathrm{X}_{1}, \mathrm{X}_{2}, \mathrm{X}_{3}=\left\{\mathrm{N}\left(\mathrm{CH}_{3}\right)_{2}, \mathrm{NSi}\left(-\mathrm{CH}_{2}-\right)_{2} \mathrm{H}, \mathrm{NSi}\left(-\mathrm{CH}_{2}-\right)_{3}\right\}$

Figure 18. Modification of AHPCS with $\mathrm{Hf}\left(\mathrm{NEt}_{2}\right)_{4}$ leading to two silicon environments in the resulting preceramic polymer (Reproduced with permission ${ }^{[187]}$; we acknowledge the Royal Society of Chemistry for the reproduced material).

$2200{ }^{\circ} \mathrm{C}$, and led to dense monolithic $\mathrm{HfC}_{x} \mathrm{~N}_{1-x} / \mathrm{SiC}$ nanocomposites, highlighting homogeneously embedded hafnium carbonitride $\left(\mathrm{HfC}_{0.83} \mathrm{~N}_{0.17}\right)$ grains in a $\beta-\mathrm{SiC}$ matrix, encapsulated by in situ formed carbon layers. These materials were then characterized in detail regarding their dielectric properties, ${ }^{[188]}$ oxidation resistance, ${ }^{[189-191]}$ and laser ablation behavior. ${ }^{[192]}$ $\mathrm{HfC}_{x} \mathrm{~N}_{1-x} / \mathrm{SiC}$ nanocomposites display improved laser ablation resistance compared to pure $\mathrm{SiC}$-based monoliths ${ }^{[192]}$ and are especially suited for electromagnetic shielding in harsh environment. ${ }^{[188,190]}$ It was reported that the additional incorporation of tantalum (Ta) in the $\mathrm{HfC}_{x} \mathrm{~N}_{1-x}$ phase leads to an enhanced sintering ability of the oxide scale and to an improved oxidation resistance via a short pre-oxidation step at temperatures sufficiently high to activate the formation of silica. ${ }^{[189,192]}$

The last - but highly important - method to reach multielement polymers with metal from the group 4 elements is the molecular synthesis of single-source precursors. This route is very useful especially in order to control the chemical composition of the preceramic precursor, and in fine of the ceramic, at the molecular scale. Upon salt metathesis reactions of zirconcene dichloride, methylphenyldichlorosilane, and dilithioacetylene, Cai et al. synthesized a $\mathrm{ZrC} / \mathrm{SiC}$ nanocomposite precursor according to Figure 19. ${ }^{[193]}$
Thus, the prepared polymer dissolves well in different solvents, such as THF, toluene, and chloroform etc. The obtained polymer could be converted to nanosized $\mathrm{ZrC} / \mathrm{C} / \mathrm{SiC}$ composites at a relatively low temperature, i.e., $1400{ }^{\circ} \mathrm{C}$ with a ceramic yield of over $52 \mathrm{wt} \%$. Starting with oxide compounds, $\mathrm{Li}$ et al. detailed the synthesis of a polymer with $\mathrm{Si}$ and $\mathrm{Zr}$ in its structure. ${ }^{[194]}$ They used the reaction of hydrolysis/condensation between tetraethoxysilane $\left(\mathrm{Si}\left(\mathrm{OC}_{2} \mathrm{H}_{5}\right)_{4}\right.$ and zirconium oxychloride octahydrate $\left(\mathrm{ZrOCl}_{2} \cdot 8 \mathrm{H}_{2} \mathrm{O}\right)$ in the presence of phenol, paraformaldehyde and acetylacetone. The as-obtained precursor yielded $\mathrm{ZrC} / \mathrm{SiC} / \mathrm{C}$ ceramics after pyrolysis up to $1800{ }^{\circ} \mathrm{C}$. However, $\mathrm{SiO}_{2}$ and $\mathrm{ZrO}_{2}$ phases were still present in the powders. Focusing on the titanium chemistry, Liu et al. used the incorporation of both $\mathrm{Ti}$ and $\mathrm{Si}$ in the backbone of a hyperbranched polycarbosilane labelled HPCS derived from Grignard coupling of a mixture made of trichloro(chloromethyl) silane $\left(\mathrm{Cl}_{3} \mathrm{SiCH}_{2} \mathrm{Cl}\right), \mathrm{Cp}_{2} \mathrm{TiCl}_{2}, \quad$ and dichloromethyl(chloromethyl)silane $\left(\mathrm{Cl}_{2} \mathrm{Si}\left(\mathrm{CH}_{3}\right) \mathrm{CH}_{2} \mathrm{Cl}\right)$ followed by $\mathrm{LiAlH}_{4}$ reduction according to Figure 20. ${ }^{[195]}$

The thermal decomposition of the final liquid hyperbranched structure denoted as HPTiCS indicated a ceramic yield of $76 \mathrm{wt} \%$ at $1200{ }^{\circ} \mathrm{C}$ (higher by around $31 \%$ than that of the ceramic yield measured with the pure hydridopolycarbosilane) and led to $\mathrm{TiC} /$ $\mathrm{SiC}$ composites.
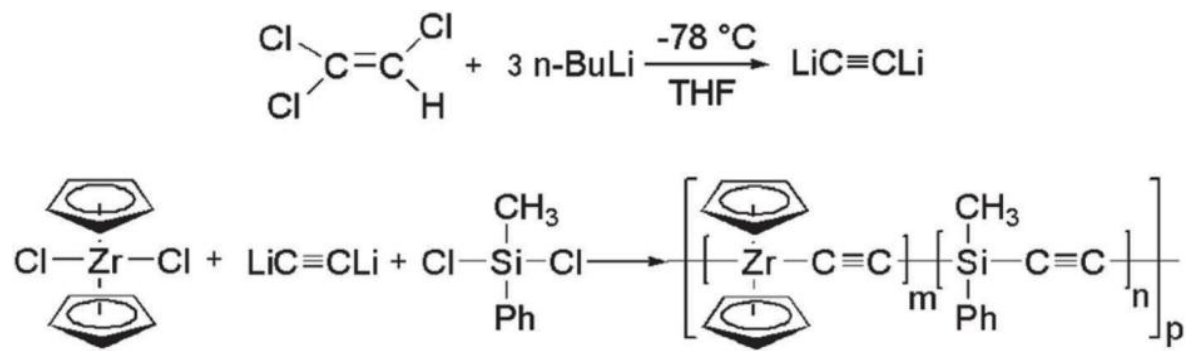

Figure 19. Synthesis of a Zr and Si containing poly-yne polymer used as a single-source precursor for the synthesis of ZrC/SiC nanocomposites. ${ }^{\text {[193] }}$ 


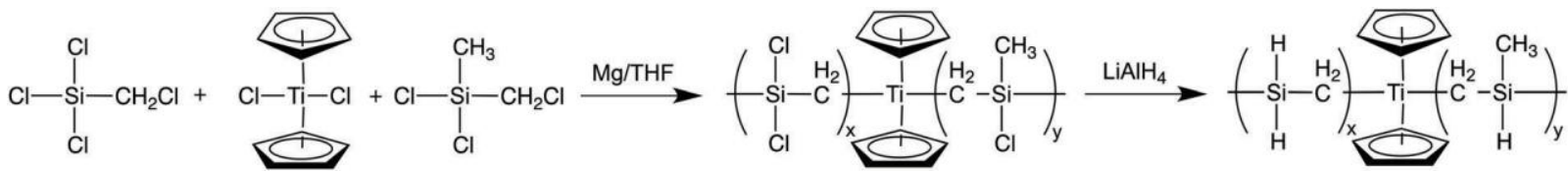

Figure 20. Two-step synthesis of a polymeric single-source precursor containing Ti and Si mixed at molecular scale. ${ }^{[195]}$

An original approach was recently described, using organolithium reagents instead of organomagnesium compounds. Moreover, the reactivity of the cyclopendatienyl groups from the zirconocene dimethyl $\left(\mathrm{Cp}_{2} \mathrm{Zr}\left(\mathrm{CH}_{3}\right)_{2}\right)$ was investigated this time. Wang et al. synthesized three preceramic polymers from an intermediate dilithiozirconocene complex as a key $\mathrm{Zr}-\mathrm{Li}$ salt obtained by the reaction of $\mathrm{Cp}_{2} \mathrm{Zr}\left(\mathrm{CH}_{3}\right)_{2}$ with tetramethylethylenediamine (TMEDA) and butyl lithium $(n-\mathrm{BuLi})$ according to Figure 21. ${ }^{[196]}$

Di- and trifunctional chlorosilanes were employed to react with the $\mathrm{Zr}$-Li salt. After removal of $\mathrm{LiCl}$ by filtration, the respective polymers were obtained (Figure 17). The polymer containing a vinyl group attached to the silicon atoms displayed the highest ceramic yield of $77 \mathrm{wt} \%$ under argon atmosphere at $800{ }^{\circ} \mathrm{C}$. Annealing experiments from 1000 to $2000{ }^{\circ} \mathrm{C}$ showed the crystallization from zirconium silicate $\left(\mathrm{ZrSiO}_{4}\right)$ and zirconia $\left(\mathrm{ZrO}_{2}\right)$ at lower temperature to $\mathrm{ZrC}$ at higher temperature. The prepared micrometer-sized spheres were shown to possess interesting electromagnetic wave absorbing capacity. ${ }^{[196]}$

It is also worth mentioning two other studies using the monomer route: Firstly, bis(cyclopentadienyl)hafnium dichloride $\left(\mathrm{Cp}_{2} \mathrm{HfCl}_{2}\right)$ and trans-1,4-dibromo-2-butene were reacted in the presence of magnesium powder in THF to yield a macromolecular $\mathrm{HfC}$ precursor. A chain termination with chloromethyltrimethylsilane $\left(\left(\mathrm{CH}_{3}\right)_{3} \mathrm{SiCH}_{2} \mathrm{Cl}\right)$ is then added to introduce silicon into the structure of the polymer. ${ }^{[197]}$ This preceramic precursor exhibited a good solubility in common organic solvents, and pyrolysis at $1600{ }^{\circ} \mathrm{C}$ resulted in $\mathrm{HfC} / \mathrm{SiC}$ nanocomposite ceramics. Secondly, a polycarbosilane was reacted with zirconocene at the end of the silicon polymer chain. ${ }^{[198]}$ Zhang et al. used a zirconocene as a catalyst with metallic sodium $(\mathrm{Na})$ for an insertion of 1-methylsilene $\left(\mathrm{H}\left(\mathrm{CH}_{3}\right)\right.$ $\left.\mathrm{Si}^{1} / \mathrm{CH}_{2}\right)$ into a preceramic precursor. The reaction product was denoted as polyzirconocenecarbosilane.

Metallic sodium was used to in-situ obtain 1-methylsylene, which polymerizes spontaneously at the Na-surface to PCS with zirconocene at the chain end groups. The thermal decomposition of the polymer with narrow molar-mass dispersity $\left(M_{\mathrm{w}} / M_{\mathrm{n}}\right)$ led to $\mathrm{ZrC} / \mathrm{SiC}$ ceramic composites with a $\mathrm{ZrC}$ concentration of about $15 \mathrm{wt} \%$. This method was extended to titanocene and hafnocene, with apparently attractive rheological properties for fiber melt spinning.

In 2012, Li et al. reported mixing a polyzirconoxanesal with boric acid and a poly(methylsilylene)ethynylene to produce $\mathrm{ZrB}_{2} / \mathrm{ZrC} / \mathrm{SiC}$ composites by pyrolysis at $1400{ }^{\circ} \mathrm{C}$ under argon. ${ }^{[141]}$ Following this study, He et al. reported the design of $\mathrm{ZrB}_{2} / \mathrm{SiC}$ nanocomposites via a precursor route based on a similar simple one-pot method. ${ }^{[199]}$ In this approach, a $\mathrm{ZrB}_{2}$ precursor and a polycarbosilane ( $\mathrm{SiC}$ precursor) were mixed in the desired ratio to form a molecular hybrid compound as a $\mathrm{ZrB}_{2} / \mathrm{SiC}$ precursor with a targeted $\mathrm{ZrB}_{2}$-to-SiC volume ratio of $25 \%$. After pyrolysis at $1300^{\circ} \mathrm{C}$, a ceramic yield close to $61 \mathrm{wt} \%$ has been measured and $\mathrm{t}-\mathrm{ZrO}_{2}$ and $\beta$-SiC phases were identified exclusively by $\mathrm{X}$-ray powder diffraction. Above this temperature, reaction of $\mathrm{ZrO}_{2}$ with $\mathrm{B}_{2} \mathrm{O}_{3}$ and $\mathrm{C}$ occurred and led to the formation of the $\mathrm{ZrB}_{2}$ phase along with $\mathrm{SiC}$. Thus, after pyrolysis at $1700{ }^{\circ} \mathrm{C}$ for $4 \mathrm{~h}$, a nanocomposite made of $\mathrm{ZrB}_{2}$ nanoparticles embedded within a $\mathrm{SiC}$ matrix was generated, although $\mathrm{ZrC}$ was identified as an additional phase present in the powders. Later, the same authors performed spark plasma sintering (SPS) of these powders by changing the $\mathrm{ZrB}_{2}$-to-SiC volume ratio from 6.4 to $61.5 \mathrm{vol} \%$ and investigated the mechanical properties of the as-prepared pieces. ${ }^{[200]}$ SPS was performed at $1600{ }^{\circ} \mathrm{C}$ for
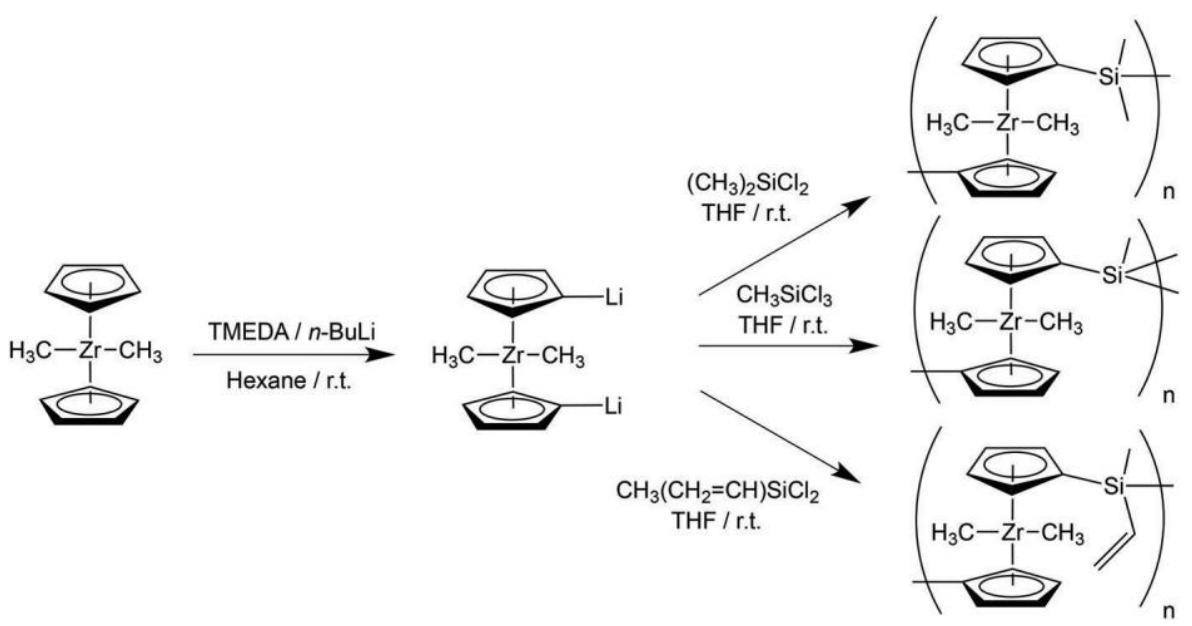

Figure 21. Synthesis of preceramic polymers via the reaction of dilithiozirconocene complex with various chlorosilanes. ${ }^{[196]}$ 
30 min under an argon atmosphere and a uniaxial pressure of $35 \mathrm{MPa}$. As expected, the Vicker's hardness of the monolithic samples increased with the increase of the density of the materials from $7.420 . \mathrm{B} \mathrm{GPa}$ (relative density of $87.6 \%$ ) to 17.54 \%.9 GPa (relative density of $99.1 \%$ ).

(Nano)Composites with Si-B-C-N Matrix as Silica Former: Adding boron to $\mathrm{Si}-\mathrm{C}-\mathrm{N}$ ceramics, i.e., leading to silicon boron carbonitride $(\mathrm{Si}-\mathrm{B}-\mathrm{C}-\mathrm{N})$ ceramics, improves the thermal stability of the amorphous structure of $\mathrm{Si}-\mathrm{C}-\mathrm{N}$ ceramics in terms of crystallization and decomposition. ${ }^{[201]}$ This phenomenon is related with the strong local covalent bonds associated with the presence of boron in SiBCN. As a consequence, the carbothermal reaction of $\mathrm{Si}_{3} \mathrm{~N}_{4}$ occurring in $\mathrm{Si}-\mathrm{C}-\mathrm{N}$ ceramics is shifted to higher temperature. The use of this amorphous inorganic network appears also to be beneficial for the high temperature creep behavior of these multicomponent ceramics. (Nano)composites with a $\mathrm{Si}-\mathrm{B}-\mathrm{C}-\mathrm{N}$ matrix have been prepared following the synthesis process implemented for dense $\mathrm{SiC} /$ $\mathrm{HfC}_{x} \mathrm{~N}_{1-x}$-based ultra-high temperature ceramic nanocomposites. ${ }^{[187]}$ A commercially available polysilazane (HTT1800 (now Durazane $^{1}$ 1800), Merck)) was modified with $\mathrm{Hf}\left(\mathrm{NEt}_{2}\right)_{4}$ and $\mathrm{BH}_{3} \cdot \mathrm{SMe}_{2}$ (Figure 22) and subsequently cross-linked and pyrolyzed. ${ }^{[202]}$

The presence of Hf and B within the molecular structure of the polysilazane leads to low-temperature phase separation processes within the resulting $\mathrm{Si}-\mathrm{Hf}-\mathrm{B}-\mathrm{C}-\mathrm{N}$. Depending on the annealing atmosphere, $\mathrm{HfC} / \mathrm{HfB}_{2} / \mathrm{SiC}$ (annealing in argon) and $\mathrm{HfN} / \mathrm{Si}_{3} \mathrm{~N}_{4} / \mathrm{SiBCN}$ (annealing in nitrogen) nanocomposites were obtained. The $\mathrm{Si}-\mathrm{Hf}-\mathrm{B}-\mathrm{C}-\mathrm{N}$ precursor could be warm-pressed after cross-linking at $250{ }^{\circ} \mathrm{C}$ then pyrolyzed and annealed to $1300{ }^{\circ} \mathrm{C}$ to form dense pieces. ${ }^{[203]}$ The oxidation behavior of these bulk samples (and powders) was studied at $1200-1400{ }^{\circ} \mathrm{C}$ in air. The measurement of the surface-specific weight gain as a function of the isothermal oxidation time showed that both, powder and monolithic samples, exhibited a parabolic oxidation behavior characterized by low parabolic rates. Observations of the oxide scale that formed on the monoliths at different oxidation temperatures revealed that a continuous oxide scale consisting of borosilicate, silica (cristobalite), $\mathrm{m}$ - and $\mathrm{t}-\mathrm{HfO}_{2}$ formed at temperatures below $1300{ }^{\circ} \mathrm{C}$, limiting the capacity for oxygen transport. At temperatures above $1300{ }^{\circ} \mathrm{C}$, oxide evaporation increased and the oxide scale became discontinuous and consisted of silica, $\mathrm{HfSiO}_{4}$, and $\mathrm{m}$ - and $\mathrm{t}-\mathrm{HfO}_{2}$, and large pores were formed in the bulk. Alternatively, the molecular $\mathrm{Si}-\mathrm{Hf}-$ B-C-N precursor was cross-linked then pyrolyzed at $900{ }^{\circ} \mathrm{C}$ to deliver powders that could be sintered by SPS at 1850 or $1950{ }^{\circ} \mathrm{C}$ into dense monolithic samples. ${ }^{[204]}$ The high hardness and high elastic modulus of the dense pieces highlighted superior mechanical properties as compared to other polymer-derived ceramics, which rely on their phase compositions and their fine microstructure. The investigation of the oxidation of the prepared dense ceramic nanocomposites at high temperature revealed that the parabolic oxidation rates of $\mathrm{Si}-\mathrm{Hf}-\mathrm{C}-\mathrm{N}$ were comparable to those of ultra-high temperature ceramics such as metal-diboride/SiC composites, whereas the parabolic oxidation rates of $\mathrm{Si}-\mathrm{Hf}-$ $\mathrm{B}-\mathrm{C}-\mathrm{N}$ were several orders of magnitude lower than those reported for UHTCs and even lower than values reported for $\mathrm{SiC}$. Additionally, the $\mathrm{Si}-\mathrm{Hf}-\mathrm{B}-\mathrm{C}-\mathrm{N}$ precursor could be used to infiltrate carbon fiber preforms $\left(\mathrm{C}_{\mathrm{f}}\right)$ and form after curing and pyrolysis $\mathrm{C}_{\mathrm{f}} / \mathrm{Si}-\mathrm{Hf}-\mathrm{B}-\mathrm{C}-\mathrm{N}$ composites. ${ }^{[205,206]}$ These ceramic matrix composites (CMCs) were tested regarding hydrothermal corrosion and laser ablation tests. The $\mathrm{C}_{\mathrm{f}} / \mathrm{Si}-\mathrm{Hf}-\mathrm{B}-\mathrm{C}-\mathrm{N}$ composites exhibited enhanced resistance towards hydrothermal corrosion as compared to $\mathrm{C}_{\mathrm{f}} / \mathrm{Si}-\mathrm{C}-\mathrm{N}$ due to the improved kinetics upon $\mathrm{Hf}$ and $\mathrm{B}$ incorporation. Additionally, a tight $\mathrm{C}_{\mathrm{f}} /$ matrix interface (which is rather disadvantageous for mechanical behavior) was found to be beneficial for improved corrosion behavior in $\mathrm{C}_{\mathrm{f}} / \mathrm{Si}-\mathrm{Hf}-\mathrm{B}-\mathrm{C}-\mathrm{N}$ composites. ${ }^{[205]}$ Various ablation mechanisms occurred in three distinct ablation regions, as detected by the study of the evolution of microstructure and phase composition of the CMCs by scanning electron microscopy (SEM) and energy dispersive spectroscopy $\left.(\mathrm{EDS})^{[206]}: 1\right)$ in the central region, the erosion of $\mathrm{C}_{\mathrm{f}} / \mathrm{Si}-\mathrm{Hf}-\mathrm{B}-\mathrm{C}-\mathrm{N}$ is controlled by the sublimation of the components of the $\mathrm{CMCs} ; 2$ ) in the transition region, the degradation of $\mathrm{C}_{\mathrm{f}} / \mathrm{Si}-\mathrm{Hf}-\mathrm{B}-\mathrm{C}-\mathrm{N}$ is dominated by the passive
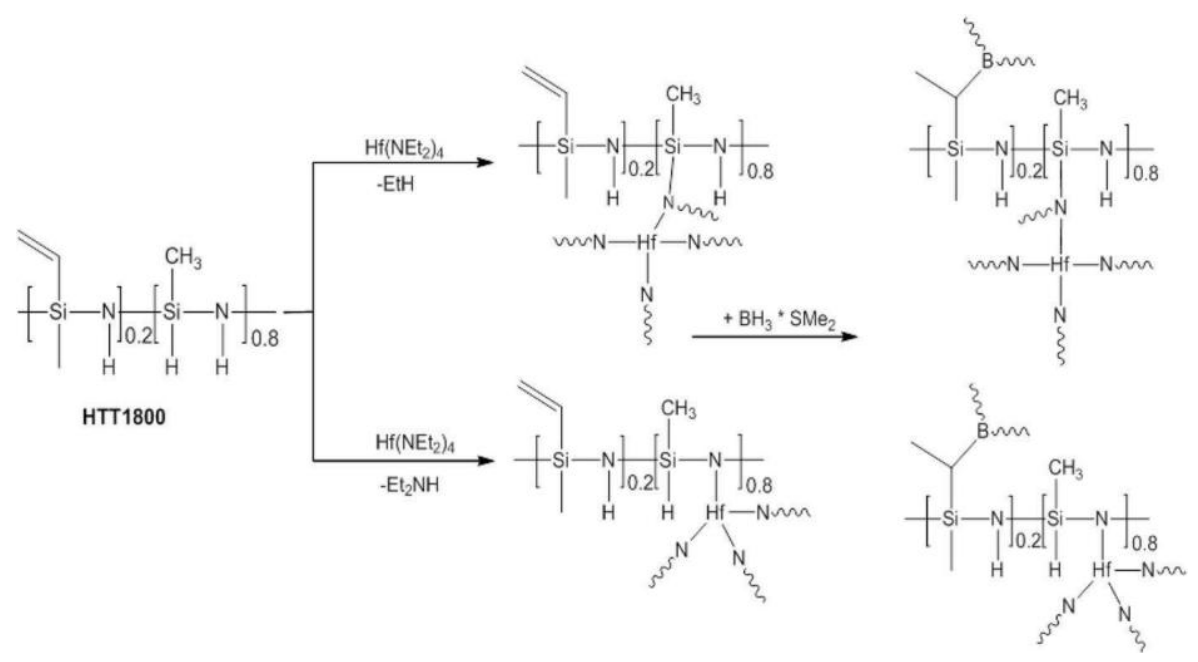

Figure 22. Modification of $\mathrm{HTT} 1800$ with $\mathrm{Hf}\left(\mathrm{NEt}_{2}\right)_{4}$ and $\mathrm{BH}_{3} \cdot \mathrm{SMe}_{2}$ (Reproduced with permission. ${ }^{[202]}$ Copyright, ACS, 2014) 
oxidation of the Hf-containing components and the active oxidation of the fibers and Si-containing components; 3 ) in the outer region, the pronounced degradation process of $\mathrm{C}_{\mathrm{f}} / \mathrm{Si}-$ $\mathrm{Hf}-\mathrm{B}-\mathrm{C}-\mathrm{N}$ is the passive oxidation of the Si-containing components. It has been found that the ablation mechanism and the microstructure evolution of CMCs are mainly dependent on the local temperature which directly depends on the distance from the laser spot and the thermal conductivity of the carbon fibers. Similarly, a hafnium chloride compound has been used to modify a liquid polyborosilazane containing borazine rings as bridges between two monomeric silazane units. ${ }^{[207]}$ After pyrolysis at $1100{ }^{\circ} \mathrm{C}$ in an argon atmosphere, the final material consisted of $\mathrm{HfN}$ nanoparticles embedded in a $\mathrm{Si}-\mathrm{B}-\mathrm{C}-\mathrm{N}$ matrix. The HfN nanoparticles distributed uniformly in the $\mathrm{Si}-\mathrm{B}-\mathrm{C}-\mathrm{N}$ matrix provided an excellent oxidation resistance: the HfN/Si-B-C-N nanocomposite was shown to be more oxidation-resistive with a weight loss of $2.8 \mathrm{wt} \%$ at $1500{ }^{\circ} \mathrm{C}$ in air, compared to a weight loss of $5.4 \mathrm{wt} \%$ for $\mathrm{Si}-\mathrm{B}-\mathrm{C}-\mathrm{N}$ ceramics under the same condition.

The addition of $\mathrm{Zr}$ in polymer-derived $\mathrm{Si}-\mathrm{B}-\mathrm{C}-\mathrm{N}$ ceramics through the modification of a liquid polyborosilazane with $\mathrm{Cp}_{2} \mathrm{ZrCl}_{2}$ according to different weight ratios has been also reported. ${ }^{[208]}$ In particular, fibers were prepared from this polymer to be cured with a $\mathrm{BCl}_{3} / \mathrm{N}_{2}$ mix flow gas, then pyrolyzed and annealed at $1400{ }^{\circ} \mathrm{C}$ under Ar. The Zr-modified $\mathrm{Si}-\mathrm{B}-\mathrm{C}-\mathrm{N}$ ceramic fibers were amorphous after pyrolysis at $1200{ }^{\circ} \mathrm{C}$. As the temperature was increased to $1400{ }^{\circ} \mathrm{C}$, crystalline phases, namely $\mathrm{ZrC}_{x} \mathrm{~N}_{y}, \mathrm{ZrB}_{2}$, and $\mathrm{Si}_{3} \mathrm{~N}_{4}$ were identified. $\mathrm{Zr}$ was also shown to improve the oxidation resistance of the $\mathrm{Si}-\mathrm{B}-\mathrm{C}-\mathrm{N}$ ceramics as reported for the $\mathrm{Hf}$ counterpart.

\section{Conclusions and Perspectives}

The polymer-derived ceramic (PDC) route represents a unique preparative access to UHTCs and their derived (nano)composites containing silica formers. These materials possess adjustable phase compositions and microstructures according to the fact that the chemical composition of the materials is controlled at a molecular scale. Thus, two strategies may be applied to deliver UHTC: 1) methods using chemical modifications of UHT-metal containing alkoxides with, e.g., (poly)alcohols, (poly)acetates, or other compounds such as acetylacetone, salicylic acid, etc.; and 2) methods using chemical modification of organometallic compounds such as metallocene-type compounds or other metal complexes with alkyl, alkenyl, alkynyl, or aryl ligands. In order to make accessible UHTC-containing nanocomposites (with either low or high content of silica former phase), a Sicontaining precursor is in general added to the UHTC precursor forming either precursor blends or, in the case of chemical reactions, single-source polymeric precursors which are further pyrolyzed at elevated temperatures ( $\left.1000{ }^{\circ} \mathrm{C}\right)$. It may be mentioned that typically polymeric blends are used to prepare nanocomposites with low volume fractions of silica former phase (i.e., 10-20 vol\%); whereas single-source precursors are highly suitable for preparing nanocomposites with high content of silica former phase (i.e., 80-90 vol\%).

There are obvious advantages of the polymeric-precursorbased synthesis methods of UHTCs and their nanocomposites, among them, e.g., nanoscopic particle size, high purity materials, relatively low synthesis temperatures. However, specific issues related to the use of polymeric/organometallic precursors should be also mentioned such as relatively high synthetic efforts (especially for the single-source precursors) or, in some cases, the environmental sensitivity of the polymeric precursors (i.e., for hydrolysis, oxidation processes). The industrial potential of UHTCs and derived (nano)composites is nevertheless evident, despite the PDCs process needs to be further developed in details for industrial and technological applications, e.g., raw materials availability, process scalability, etc. In particular, following aspects should be intensively addressed in the future in order to provide a rational design of UHTCs and their derived (nano)composites with tailored compositions, microstructures and properties: 1) a straightforward synthetic access to single-source precursors with a detailed knowledge on their chemical compositions and molecular architectures; 2) a fundamental understanding of the polymer-to-ceramic conversion process; 3 ) polymer chemistry - rheology correlation to develop the processability of these polymers and design complex textures and morphologies of materials; 4) joint and tailored experimental and computational studies are necessary in order to assess the properties of the UHTCs and their derived (nano)composites and to understand how the microstructural features of the materials affect their properties; and 5) detailed short and long-term analysis of their high-temperature behavior and mechanical properties (hardness, Young modulus, fracture toughness, etc.). It is anticipated that polymer-derived UHTCs and their derived (nano)composites have the potential to provide specific functionalities as well as improved and/or extended properties to be applied in particular in the societal relevant fields of energy conversion and future aeronautics and reentry systems.

\section{Acknowledgements}

The authors team is grateful to Prof. Yanchun Zhou (Aerospace Research Institute of Materials and Processing Technology, Beijing, China) for encouraging to compile the present review on polymer-derived UHTC systems. El and RR thank the German Science Foundation (DFG, Bonn, Germany) for financial support (project "Micropatterned polymer-derived ceramic catalysts and sensors"). El furthermore acknowledges the EU COST Action CM1302 (Smart Inorganic Polymers) and the Heisenberg Program of DFG. PK gratefully acknowledges support by the National Science Foundation (CMMI-1634448 and OISE 1743701).

\section{Keywords}

physical properties, preceramic polymers, refractoriness, synthesis, thermodynamics, UHTC (nano)composites, ultra-high temperature ceramics (UHTCs) 



\section{References:}

[1] E. J.Wuchina, E. Opila, M. M. Opeka, W. Fahrenholtz, I. G. Talmy, Interface 2007, 16, 30.

[2] W. G. Fahrenholtz, G. E. Hilmas, Scr. Mater. 2017, 129, 94.

[3] E. Wuchina, E. Opila, M. Opeka, W. Fahrenholtz, I. Talmy, Electrochem. Soc. Interface 2007, 16, 30.

[4] T.H. Squire, J. Marschall, J. Eur. Ceram. Soc. 2010, 30, 2239.

[5] D. M. Van Wie, D. G. Drewry, D. E. King, C. M. Hudson, J. Mater. Sci. 2004, 39, 5915.

[6] G. B. Fairbank, C.J. Humphreys, A. Kelly, C. N. Jones, Intermetallics 2000, 8, 1091.

[7] G. E. Fuchs, Kirk-Othmer Encyclopedia of Chemical Technology, John Wiley \& Sons, Inc., Hoboken, New Jersey, USA 2000.

[8] N. R. Muktinutalapati, Advances in Gas Turbine Technology (Ed: E. Benini), Intech, Rijeka, Croatia 2011, pp. 293-314.

[9] R. C. Reed, The Superalloys - Fundamentals and Applications, Cambridge University Press, Cambridge, UK 2006.

[10] K. E. Spear, S. Visco, E. J. Wuchina, E. D. Wachsman, Interface2006, $15,48$.

[11] Y. D. Blum, H. J. Kleebe, J. Mater. Sci. 2004, 39, 6023.

[12] M. M. Opeka, I. G. Talmy, J. A. Zaykoski, J. Mater. Sci. 2004, 39, 5887.

[13] W. G. Fahrenholtz, G. E. Hilmas, I. G. Talmy, J. A.Zaykoski, J.Am. Ceram. Soc. 2007, 90, 1347.

[14] A. Paul, D. D. Jayaseelan, S. Venugopal, E.Zapata-Solvas, J. Binner, B. Vaidhyanathan, A. Heaton, P. Brown, W. E. Lee, Am. Ceram. Soc. Bull. 2012, 91, 22.

[15] W. G. Fahrenholtz, G. E. Hilmas, Int. Mater. Rev. 2012, 57, 61

[16] A. L. Chamberlain, W. G. Fahrenholtz, G. E. Hilmas, D. T. Ellerby, J. Am. Ceram. Soc. 2004, 87, 1170.

[17] S. N. Dub, A. A. Goncharov, S. S. Ponomarev, V. B. Filippov, G. N. Tolmacheva, A. V. Agulov, J. Superhard Mater. 2011 33, 151.

[18] B.Predel, B-Ba...Cu-Zr:SupplementtoSubvolumes IV/5B, IV/ $5 \mathrm{C}$ and IV/5D (Ed: B. Predel), Springer Berlin Heidelberg, Berlin, Heidelberg 2012, p. 77-78.

[19] X. OuYang, F. Yin, J. Hu, Y. Liu, Z. Long, J. Phase Equilib. Diff. 2017, $38,874$.

[20] K. Frisk, A. Fernández Guillermet, J. Alloy. Compd. 1996, 238, 167.

[21] A. A. A. P. da Silva, F. Ferreira, B. B. de Lima-Kuhn, G. C. Coelho,

C. A. Nunes, P. Vilasi, J.-M. Fiorani, N. David, M. Vilasi, CALPHAD 2018, 63, 107.

[22] G. Cacciamani, P. Riani, F. Valenza, Calphad 2011, 35, 601.

[23] J. W. Lawson, C. W. Bauschlicher, M. S. Daw, J. Am. Ceram. Soc. 2011, 94, 3494.

[24] H. M. Xiang, Z. H. Feng, Z. P.Li, Y. C.Zhou, J. Am. Ceram. Soc. 2017, 100, 3662.

[25] G. Zhang, Y.X. Zhao, J.Zhu, Y. J. Hao, L. Zhang, Int. J. Mod. Phys. B 2018, 32, 15.

[26] H. Li, L. T. Zhang, Q. F. Zeng, J. J. Wang, L. F. Cheng, H. T. Ren, K. Guan, Comput. Mater. Sci. 2010, 49, 814.

[27] J. Li, C. Z. Fan, Phys. Chem. Chem. Phys. 2015, 17, 1180.

[28] A. G. Van der Geest, A. N. Kolmogorov, CALPHAD2014, 46, 184

[29] D. Lee, J. J. Vassak, K. J. Zhao, Nano Lett. 2015, 15, 6553.

[30] Y. Pan, H. W. Huang, X. Wang, Y. H. Lin, Comput. Mater. Sci. 2015, 109, 1.

[31] A. Goldstein, Y. Geffen, A. Goldenberg, J. Am. Ceram. Soc. 2001, 84, 642.

[32] S. C. Zhang, G. E. Hilmas, W. G. Fahrenholtz, J. Am. Ceram. Soc. 2006, 89, 1544.
[33] S. K. M. Pathak, S. Das, S. K. Das, P. Ramachandrarao, J. Mater. Res. 2000, 15, 2499.

[34] H. J. Feng, J. J. Moore, D. G. Wirth, Metall. Trans. A 1992, 23, 2373.

[35] S. V. Meschel, O. J. Kleppa, J. Alloy. Compd. 2001, 321, 183.

[36] L. Topor, O. J. Kleppa, J. Chem. Thermodyn. 1985, 17, 1003.

[37] V. A. Medvedev, G. A. Bergman, V. P. Vasil'ev, L. V. Gurvich, V.S. Yungman, A. F. Vorob'ev, V. P. Kolesov, Thermal Constants of Substances, Vol. 7(Ed: V. P. Glushko) VINITI, Moscow 1974, p. 343.

[38] X. Ma, C. Li, Z. Du, W. Zhang, J. Alloy. Compd. 2004, 370, 149.

[39] E. Rudy, S. Windisch, Ternary phase equilibriums in transition metalboron-carbon-silicon systems. Part I. Related Binary System, vol. VII, Ti-B System, Aerojet-Gen. Corp., Wright-Patterson Air Force Base, Ohio, USA 1966, p. 234.

[40] M. W. J. Chase, NIST-JANAF Thermochemical Tables, American Inst. of Physics, College Park, Maryland, USA 1998.

[41] P. Ettmayer, R. Kieffer, F. Hattinger, Metall (Berlin) 1974, 28, 1151.

[42] M. Sheindlin, T. Falyakhov, S. Petukhov, G. Valyano, A. Vasin, Adv. Appl. Ceram. 2018, 117, s48.

[43] H. Okamoto, J. Phase Equilib. 1993, 14, 261.

[44] S. Sridar, R. Kumar, K. C. Hari Kumar, CALPHAD2017, 56, 102.

[45] C. Wang, M.Zinkevich, F. Aldinger, J. Am. Ceram. Soc. 2006, 89, 3751.

[46] G. K. Johnson, E. Greenberg, J. L. Margrave, W. N. Hubbard, J. Chem. Eng. Data 1967, 12, 137.

[47] S. Meschel, O. Kleppa, J. Chim. Phys. 1993, 90,349.

[48] E. Rudy, S. Windisch, Ternary Phase Equilibriums in Transition MetalBoron-Carbon-Silicon Systems. I. Related Binary Systems. 10. Systems Vanadium-Boron, Niobium-Boron, and Tantalum-Boron, AerojetGen. Corp., Wright-Patterson Air Force Base, Ohio, USA 1966, p. 119.

[49] A. D. Mah, N. L. Gellert, J. Am. Chem. Soc. 1956, 78, 3261.

[50] I. Talmy, J. Zaykoski, Ceram. Eng. Sci. Proc. 1998, 19, 105.

[51] G. J. Zhang, Z. Y. Deng, N. Kondo, J. F. Yang, T. Ohji, J. Am. Ceram. Soc. $2000,83,2330$.

[52] W. Lengauer, Handbook of Ceramic Hard Materials (Ed: R. Riedel), Wiley-VCH, Weinheim 2000, pp. 202-252.

[53] R. Pampuch, J. Eur. Ceram. Soc. 1999, 19, 2395.

[54] A. J. Perry, Powder Metall. Int. 1987, 19, 32.

[55] A. J. Perry, Powder Metall. Int. 1987, 19, 29.

[56] F. M. Charbonnier, W. A. Mackie, R. L. Hartman, T.B. Xie, J. Vac. Sci. Technol. B 2001, 19, 1064.

[57] C. E. Curtis, L. M. Doney, J. R. Johnson, J. Am. Ceram. Soc. 1954, 37, 458.

[58] P. G. Cotter, J. A. Kohn, J. Am. Ceram. Soc. 1954, 37, 415.

[59] S.-K. Sun, G.-J. Zhang, W.-W. Wu, J.-X. Liu, T. Suzuki, Y. Sakka, Scr. Mater. 2013, 69, 139.

[60] A. Zerr, G. Miehe, R. Riedel, Nat. Mater. 2003, 2, 185.

[61] J.J.Burton, R. L. Garten, AdvancedMaterials in Catalysis, Academic Press, Cambridge, Massachusetts, USA 1977.

[62] V.I.Razumovskiy, A.V.Ruban, J. Odqvist, D.Dilner,P.A.Korzhavyi, CALPHAD 2014, 46, 87.

[63] X. X. Yu, C. R. Weinberger, G. B. Thompson, Acta Mater. 2014, 80, 341.

[64] S. Vorotilo, K. Sidnov, I. Y. Mosyagin, A. V. Khvan, E. A. Levashov, E. I. Patsera, I. A. Abrikosov, J. Alloy. Compd. 2019, 778, 480.

[65] H. Okamoto, Bull. Alloy Phase Diagr. 1990, 11, 146.

[66] C. R. Weinberger, X. X. Yu, H. Yu, G. B. Thompson, Comput. Mater. Sci. 2017, 138, 333.

[67] J. Zhang, A. R. Oganov, X. F. Li, H. Y. Niu, Phys. Rev. B2017, 95, 020103.

[68] F. Predel, Phase Equilibria, Crystallographic and Thermodynamic Data of Binary Alloys: K-O ... Y-Zr (Ed: F. Predel), Springer Berlin Heidelberg, Berlin, Heidelberg 2016, pp. 89-89. 
[69] K. Frisk, J. Alloy. Compd. 1998, 278, 216.

[70] A. N. Christensen, B. Lebech, Acta Crystallograph. Sect. B1978, 34, 261.

[71] N. Terao, Jpn. J. Appl. Phys. 1971, 10, 248.

[72] C. Stampfl, A. J. Freeman, Phys. Rev. B2005, 71, 024111.

[73] P. Kroll, Phys. Rev. Lett. 2003, 90, 125501.

[74] P. Kroll, T.Schroter, M. Peters, Angew. Chem. Int. Edit. 2005, 44, 4249.

[75] H. Alkhaldi, P. Kroll, J. Phys. Chem. C 2019, 123, 7054.

[76] A. Abdollahi, Phys. B (Amsterdam, Neth.) 2013, 410, 57.

[77] Q.-J. Hong, A. van de Walle, Phys. Rev. B 2015, 92, 020104.

[78] M. Pirani, H. Alterthum, Z. Elektrochem. Angew. Phys. Chem. 1923 , $29,5$.

[79] E. Rudy, J. Progulski, Planseeber. Pulvermetall. 1967, 15, 13.

[80] T. Huepf, C. Cagran, G. Pottlacher, EPJ Web Conf. 2011, 15, 01018.

[81] O. Cedillos-Barraza, D. Manara, K. Boboridis, T. Watkins, S. Grasso, D. D. Jayaseelan, R. J. M. Konings, M. J. Reece, W. E. Lee, Sci. Rep. 2016, 6, 37962.

[82] A. I. Savvatimskiy, S. V. Onufriev, S. A. Muboyadzhyan, J. Mater. Res. 2017, 32, 1287.

[83] A. I. Savvatimskiy, S. V. Onufriev, S. A. Muboyadzhyan, J. Eur. Ceram. Soc. 2019, 39, 907.

[84] A. Kondratyev, S. Muboyajan, S. Onufriev, A. Savvatimskiy, J. Alloy. Compd. 2015, 631, 52.

[85] S. V. Onufriev, A. M. Kondratiev, A. I. Savvatimskiy, G. E. Val'yano S. A. Muboyajan, High Temp. 2015, 53, 455.

[86] C. Agte, H. Alterthum, Z. Tech. Phys. 1930, 11, 182.

[87] E. Ionescu, H. J. Kleebe, R. Riedel, Chem. Soc. Rev. 2012, 41, 5032.

[88] G. Mera, M. Gallei, S. Bernard, E. lonescu, Nanomaterials-Basel 2015, 5, 468.

[89] G. Mera, E. Ionescu, Encyclopedia of PolymerScience and Technology, John Wiley \& Sons, Inc., Hoboken, New Jersey, USA 2013.

[90] L. V. Interrante, L. E. Carpenter, C. Whitmarsh, M. Hackney, Electrochem. Soc. 1986, 133, C119.

[91] D. M. Narsavage, L. V. Interrante, P. S. Marchetti, G. E. Maciel, Chem. Mater. 1991, 3, 721.

[92] G. Fritz, B. Raabe, Z. Anorg. Allg. Chem. 1956, 286, 149.

[93] G. Fritz, B. Raabe, Angew. Chem. Int. Edit. 1956, 68, 381.

[94] G. Fritz, B. Raabe, Z. Naturforsch. Pt. B 1956, 11, 57.

[95] S. Yajima, J. Hayashi, M. Omori, Chem. Lett. 1975, 931.

[96] S. Yajima, Y. Hasegawa, K. Okamura, T. Matsuzawa, Nature 1978 273, 525.

[97] S. Yajima, Y. Hasegawa, J. Hayashi, M. limura, J. Mater. Sci. 1978 13, 2569.

[98] T. Shimoo, F. Toyoda, K. Okamura, J. Mater. Sci. 2000, 35, 3301

[99] S. Yajima, Philos. Trans. Royal Soc. A 1980, 294, 419.

[100] T. Ishikawa, S. Kajii, K. Matsunaga, T. Hogami, Y. Kohtoku, T. Nagasawa, Science 1998, 282, 1295.

[101] T. Ishikawa, Y. Kohtoku, K. Kumagawa, J. Mater. Sci. 1998, 33, 161[138] D.Liu,W.F. Qiu, T.Cai, Y.N.Sun, A.J.Zhao, T.Zhao, J.Am.Ceram.

[102] T. Ishikawa, T. Yamamura, K. Okamura, J. Mater. Sci. 1992, 27, 6627.

[103] F. Babonneau, G. D. Sorarù, J. Eur. Ceram. Soc. 1991, 8, 29.

[104] S. Kaur, G. Cherkashinin, C. Fasel, H. J. Kleebe, E. Ionescu, R. Riedel1140] D. S. Kim, M. C. Suh, S. C. Shim, J. Polym. Sci. Pol. Chem. 1998, 36, J. Eur. Ceram. Soc. 2016, 36, 3553.

[105] E. Ionescu, B. Papendorf, H. J. Kleebe, F. Poli, K. Muller, R. Riedel, J. Am. Ceram. Soc. 2010, 93, 1774.

[106] E. lonescu, B. Papendorf, H. J. Kleebe, R. Riedel, J. Am. Ceram. Soc. 2010, 93, 1783.

[107] E. Ionescu, C. Linck, C. Fasel, M. Muller, H. J. Kleebe, R. Riedel, J. Am. Ceram. Soc. 2010, 93, 241.

[108] E. lonescu, C. Terzioglu, C. Linck, J. Kaspar, A. Navrotsky, R. Riedel, J. Am. Ceram. Soc. 2013, 96, 1899.
[109] K. Thorne, S. J. Ting, C. J. Chu, J. D. Mackenzie, T. D. Getman, M. F. Hawthorne, J. Mater. Sci. 1992, 27, 4406.

[110] E. L. Sham, E. M. Farfantorres, S. Bruquegamez, J. J. Rodriguezjimenez, Solid State lonics 1993, 63-5, 45.

[111] G. Takahiro, Y. Hiroshi, H. Takaaki, B. K. Kyoko, A. Yoshimoto, Appl. Organomet. Chem. 2000, 14, 119.

[112] M. D. Sacks, C. A. Wang, Z. H. Yang, A. Jain, J. Mater. Sci. 2004, 39, 6057.

[113] M. Inoue, H. Kominami, T. Inui, J. Chem. Soc., Dalton Trans. 1991, 3331.

[114] M. Pan, J. R. Liu, M. K. Lu, D. Xu, D. R. Yuan, D. R. Chen, P. Yang, Z. H. Yang, Thermochim. Acta 2001, 376, 77.

[115] Y. Abe, T. Kudo, H. Tomioka, T. Gunji, Y. Nagao, T. Misono, J. Mater. Sci. 1998, 33, 1863.

[116] H.Y.Liu, X. Q.Hou, X. Q.Wang, Y.L.Wang, D.Xu, C.Wang,W.Du, M. K. Lu, D. R. Yuan, J. Am. Ceram. Soc. 2004, 87, 2237.

[117] X.Y.Tao, W. F. Qu, H. Li, T.Zhao, Polym. Adv. Technol.2010, 21, 300.

[118] Y.Lu, F.H.Chen, P.F.An, L. Ye,W.F. Qu, T.Zhao, RSCAdv.2016, 6,88770

[119] H. Preiss, L. M. Berger, K. Szulzewsky, Carbon 1996, 34, 109.

[120] H. Preiss, E. Schierhorn, K. W. Brzezinka, J. Mater. Sci. 1998, 33, 4697.

[121] C. N. McMahon, L. Alemany, R. L. Callender, S. G. Bott, A. R. Barron, Chem. Mater. 1999, 11, 3181.

[122] Y. Kurokawa, T. Ishizaka, M. Suzuki, J. Mater. Sci. 2001, 36, 301.

[123] X. Tao, Z. Xiang, S. Zhou, Y. Zhu, W. Qiu, T.Zhao, J. Ceram. Sci. Technol. 2016, 7, 107.

[124] H. Lang, D. Seyferth, Appl. Organomet. Chem. 1990, 4, 599.

[125] K. Inzenhofer, T. Schmalz, B. Wrackmeyer, G. Motz, Dalton Trans. 2011, 40, 4741.

[126] H. Wang, X. B. Chen, B. Gao, J. Wang, Y. D. Wang, S. G. Chen, Y. Z. Gou, Appl. Organomet. Chem. 2013, 27, 79.

[127] W. C. Tripp, H. H. Davis, H. C. Graham, Am. Ceram. Soc. Bull. 1973, 52, 612.

[128] W. G. Fahrenholtz, J. Am. Ceram. Soc. 2007, 90, 143.

[129] A. Rezaie,W.G. Fahrenholtz, G. E. Hilmas, J. Eur. Ceram. Soc. 2007, 27, 2495

[130] A. Rezaie, W. G. Fahrenholtz, G. E. Hilmas, J. Am. Ceram. Soc. 2006, $89,3240$.

[131] A. Tampieri, E. Landi, A. Bellosi, J. Therm. Anal. 1992, 38, 2657.

[132] A. P. Salikova, I. B. Ban'kovskaya, D. V. Kolovertnov, V.P. Popov, Glass Phys. Chem. 2010 36, 225.

[133] D. Sciti, M. Brach, A. Bellosi, J. Mater. Res. 2005, 20, 922.

[134] D. Sciti, M. Brach, A. Bellosi, Scr. Mater 2005, 53, 1297.

[135] I. G. Talmy, J. A.Zaykoski, M. M.Opeka, A. H.Smith, J. Mater. Res. 2006, 21, 2593.

[136] I. G. Talmy, J. A.Zaykoski, M. M. Opeka, J. Am. Ceram. Soc. 2008, 91, 2250.

[137] T.Cai, W. F. Qiu, D. Liu, W.J.Han, L. Ye, A.J.Zhao, T.Zhao, J.Am. Ceram. Soc. 2013, 96, 3023. Soc. 2014, 97, 1242.

[139] T.Cai, D. Liu, W. F. Qiu, W. J. Han, T.Zhao, J. Am. Ceram. Soc. 2018, $101,20$. 2275.

[141] Y.T.Li, W. J. Han, H. Li, J.B. Zhao, T.Zhao, Mater. Lett. 2012, 68, 101.

[142] N. Patra, W. E. Lee, ACS Appl. Nano Mater. 2018, 1, 4502.

143] P.Amoros, D. Beltran, C. Guillem, J. Latorre, Chem. Mater. 2002, 14, 1585.

[144] D. Fonblanc, D. Lopez-Ferber, M. Wynn, A. Lale, A. Soleilhavoup, A. Leriche, Y. Iwamoto, F. Rossignol, C. Gervais, S. Bernard, Dalton Trans. 2018, 47, 14580.

[145] R. T. Paine, J. F. Janik, M. Fan, Polyhedron 1994, 13, 1225. 
[146] E. Bernardo, L. Fiocco, G. Parcianello, E. Storti, P. Colombo, Materials 2014, 7, 1927.

[147] M. M. Guron, X. L. Wei, D. Welna, N. Krogman, M. J. Kim, H. Allcock, L. G. Sneddon, Chem. Mater. 2009, 21, 1708.

[148] O. Majoulet, C. Salameh, M. E. Schuster, U. B. Demirci, Y. Sugahara, S. Bernard, P. Miele, Chem. Mater. 2013, 25, 3957.

[149] M. Weinmann, A. Zern, F. Aldinger, Adv. Mater. 2001, 13, 1704.

[150] N. Hering, K. Schreiber, R. Riedel, O. Lichtenberger, J. Woltersdorf, Appl. Organomet. Chem. 2001, 15, 879.

[151] E. W. Awin, A. Lale, K. C. H. Kumar, U. B. Demirci, S. Bernard, R. Kumar, Mater. Des. 2018, 157, 87.

[152] M. C. Bechelany, V. Proust, C. Gervais, R. Ghisleni, S. Bernard, P. Miele, Adv. Mater. 2014, 26, 6548.

[153] A. Lale, V. Proust, M. C. Bechelany, A. Viard, S. Malo, S. Bernard, J. Eur. Ceram. Soc. 2017, 37, 5167.

[154] M. C. Bechelany, V. Proust, A. Lale, P. Miele, S. Malo, C. Gervais, S. Bernard, Chem. -Eur. J. 2017, 23, 832.

[155] C. Zhou, X. Gao, Y. Xu, G. Buntkowsky, Y. Ikuhara, R. Riedel, E. Ionescu, J. Eur. Ceram. Soc. 2015, 35, 2007.

[156] D. Pizon, R. Lucas, S. Foucaud, A. Maitre, Adv. Eng. Mater. 2011, 13, 599.

[157] D. Pizon, R. Lucas, S. Chehaidi, S. Foucaud, A. Maitre, J. Eur. Ceram. Soc. 2011, 31, 2687.

[158] D. Seyferth, N. Bryson, D. P. Workman, C. A. Sobon, J. Am. Ceram. Soc. 1991, 74, 2687.

[159] D. Seyferth, H. Lang, H. J. Tracy, C. Sobon, J. Borm, Abstr. Pap. Am. Chem. S 1991, 202, 359.

[160] F. Honack, R. Riedel, Adv. Eng. Mater. 2003, 5, 122.

[161] Y. M. Luo, Z. M. Zheng, C. H. Xu, X. N. Mei, Mater. Lett. 2008, 62, 3570.

[162] Y. M. Luo, Z. M. Zheng, X. N. Mei, C. H. Xu, J. Cryst. Growth2008, $310,3372$.

[163] Y. M. Luo, Z. M. Zheng, X. N. Mei, C. H. Xu, Mater. Chem. Phys. 2009, 113, 26.

[164] J.S.Yang, S.M.Dong, Y.S.Ding, Z.Wang, H.J.Zhou, B.Lu, J.Am. Ceram. Soc. 2010, 93, 2117.

[165] V. Proust, M. C. Bechelany, R. Ghisleni, M. F. Beaufort, P. Miele, S. Bernard, J. Eur. Ceram. Soc. 2016, 36, 3671.

[166] S. Yajima, T. Iwai, T.Yamamura, K. Okamura, Y. Hasegawa, J. Mater. Sci. 1981, 16, 1349.

[167] H. Ichikawa, F. Machino, S. Mitsuno, T. Ishikawa, K. Okamura, Y. Hasegawa, J. Mater. Sci. 1986, 21, 4352.

[168] Y. Song, C. Feng, Z. Tan, Y. Lu, J. Mater. Sci. Lett. 1990, 9, 1310.

[169] F. Babonneau, G. D. Soraru, J. D. Mackenzie, J. Mater. Sci.1990, 25, 3664.

[170] G. D. Soraru, A. Glisenti, G. Granozzi, F. Babonneau, J. D. Mackenzie, J. Mater. Res. 1990, 5, 1958.

[171] K. Maeda, M. Higashi, B. Siritanaratkul, R. Abe, K. Domen, J. Am. Chem. Soc. 2011, 133, 12334.

[172] G. Chollon, B. Aldacourrou, L. Capes, R. Pailler, R. Naslain, J. Mater. Sci 1998, 33, 901.

[173] S. R. Levine, E. J. Opila, M. C. Halbig, J. D. Kiser, M. Singh, J. A. Salem, J. Eur. Ceram. Soc. 2002, 22, 2757.

[174] Z. J. Yu, L. Yang, J. Y. Zhan, C. Zhou, H. Min, Q. Zheng, H. P. Xia, J. Eur. Ceram. Soc. 2012, 32, 1291.

[175] X. F. Wang, J. C. Liu, F. Hou, J. D. Hu, X. Sun, Y. C. Zhou, J. Am. Ceram. Soc. 2015, 98, 197.

[176] F. Bouzat, G. Darsy, S. Foucaud, R. Lucas, Polym. Rev. 2016, 56, 187.
[177] Q. G. Li, S. M. Dong, P.He, H. J.Zhou, Z. Wang, J. S. Yang, B. Wu, J. B. Hu, Ceram. Int. 2012, 38, 6041.

[178] J.W. Li, S. Q. Yu, Y.Zhou, M. Ge, Y. B. Qian, W. G. Zhang, Mater. Lett. 2015, 156, 72.

[179] C. Huang, Z. Wang, M. Wang, Adv. Appl. Ceram. 2016, 115, 166

[180] H. Wang, B. Gao, X. B. Chen, J.Wang, S. G. Chen, Y.Z. Gou, Appl. Organomet. Chem. 2013, 27, 166.

[181] Z. J. Yu, H. Min, J. Y. Zhan, L. Yang, Ceram. Int. 2013, 39, 3999.

[182] S. W. Li, L. T. Zhang, M. H. Huang, Z. J. Yu, H. P. Xia, Z. D. Feng, L. F. Cheng, Mater. Chem. Phys. 2012, 133, 946.

[183] X. Long, C. W. Shao, J. Wang, Y. Z. Gou, Appl. Organomet. Chem. 2018, 32, e3942.

[184] S. G. Chen, J. Wang, H. Wang, Mater. Des. 2016, 90, 84.

[185] S. G. Chen, Y. Z. Gou, H. Wang, J. Wang, J. Eur. Ceram. Soc. 2016, $36,3843$.

[186] V. V. Vijay, S. G. Nair, K. J. Sreejith, R. Devasia, J. Inorg. Organomet. $P$ 2016, 26, 302

[187] Q. B. Wen, Y.P. Xu, B. B. Xu, C. Fasel, O. Guillon, G. Buntkowsky, Z. J. Yu, R. Riedel, E. Ionescu, Nanoscale 2014, 6, 13678.

[188] Q. B. Wen, Y. Feng, Z. J. Yu, D. L. Peng, N. Nicoloso, E. lonescu, R. Riedel, J. Am. Ceram. Soc. 2016, 99, 2655.

[189] Q. B. Wen, R. Riedel, E. lonescu, Corros. Sci. 2018, 145, 191.

[190] Q. B. Wen, Z. J. Yu, Y. P. Xu, Y. Lu, C. Fasel, K. Morita, O. Guillon, G. Buntkowsky, E. Ionescu, R. Riede, J. Mater. Chem. C2018, 6, 855.

[191] Q.Wen, R. Riedel, E. lonescu, Adv. Eng. Mater. 2019, 21, 1800879.

[192] Q.Wen, X. Luan, L. Wang, X.Xu, E. Ionescu, R. Riedel, J. Eur. Ceram. Soc. 2019, 39, 2018.

[193] T.Cai, W.F. Qiu, D. Liu,W.J.Han, L. Ye, A.J.Zhao, T.Zhao, Dalton Trans. 2013, 42, 4285.

[194] C. Q. Liu, K. Z. Li, H. J. Li, S. Y. Zhang, Y. L. Zhang, X. H. Hou, J. Mater. Sci. 2015, 50, 2824.

[195] Z. J. Yu, L. Yang, H. Min, P.Zhang, A. H. Liu, R. Riedel, J. Eur. Ceram. Soc. 2015, 35, 851.

[196] Q. C. Zhang, Y. Z. Gou, J. L. Wang, H. Wang, K. Jian, Y. F. Wang, J. Eur. Ceram. Soc. 2017, 37, 1909.

[197] J. Cheng, X. Z. Wang, H. Wang, C. W. Shao, J. Wang, J. Am. Ceram. Soc. 2017, 100, 5044.

[198] Y.L. Tian, M. Ge, W. G. Zhang, X. X. Lv, S. Q. Yu, Sci. Rep. UK2015, 5,16274

[199] J.B. He, Y. Gao, Y. G. Wang, J. Y. Fang, L. N. An, Ceram. Int. 2017, 43, 1602.

J. B. He, Y. J. Cao, Y. X. Zhang, Y. G. Wang, Ceram. Int. 2018, 44, 6520. A. Viard,D. Fonblanc,M.Schmidt,A. Lale,C.Salameh, A. Soleilhavoup, M. Wynn, P. Champagne, S. Cerneaux, F. Babonneau, G. Chollon, F. Rossignol, C. Gervais, S. Bernard, Chem.-Eur. J. 2017, 23, 9076.

[202] J. Yuan, S. Hapis, H. Breitzke, Y. Xu, C. Fasel, H.-J. Kleebe, G. Buntkowsky, R. Riedel, E. Ionescu, Inorgan. Chem. 2014, 53, 10443.

[203] J. Yuan, M. Galetz, X. G. Luan, C. Fasel, R. Riedel, E. Ionescu, J. Eur. Ceram. Soc. 2016, 36, 3021.

[204] J. Yuan, D. Li, K. E. Johanns, C. Fasel, K. Durst, H. J. Kleebe, Z. J. Shen, R. Riedel, E. Ionescu, J. Eur. Ceram. Soc. 2017, 37, 5157.

[205] J. Yuan, X. G. Luan, R. Riedel, E. Ionescu, J. Eur. Ceram. Soc. 2015, 35,3329

[206] X. Luan, J. Yuan, J. Wang, M. Tian, L. Cheng, E. lonescu, R. Riedel, J. Eur. Ceram. Soc. 2016, 36, 3761.

[207] S. H. Wang, Y. C. Zhang, Y. Sun, Y. Xu, M. Yang, J. Alloy. Compd. 2016, 685, 828.

[208] X. Long, C. Shao, H. Wang, J. Wang, Ceram. Int. 2016, 42, 19206. 